\title{
Examination of source-model construction methodology for strong ground-motion simulation of multi-segment rupture during 1891 Nobi earthquake
}

\author{
Masayuki Kuriyama ${ }^{1}$ and Tomotaka Iwata $^{2}$ \\ ${ }^{1}$ Civil Engineering Research Laboratory, Central Research Institute of Electric Power Industry, \\ 1646, Abiko, Abiko-shi, Chiba 270-1194, Japan \\ ${ }^{2}$ Disaster Prevention Research Institute, Kyoto University, Gokasho, Uji-shi, Kyoto 611-0011, Japan
}

(Received December 10, 2009; Revised September 23, 2010; Accepted December 13, 2010; Online published February 28, 2011)

\begin{abstract}
We examine the construction methodology of a source model for strong ground-motion prediction of scenario earthquakes with a long active-fault zone including a multi-segment rupture case. For the multi-segment rupture event, different seismic moments are given by applying two different source-model construction methodologies: (1) a methodology based on seismological scaling relationships and (2) a methodology in an active-fault study based on the cascade model (Working Group on California Earthquake Probabilities, 1995). The difference between these methodologies is whether or not a slip of each segment depends on total rupture length. We investigate which construction methodology is more appropriate for the construction of the source model. We use the two methodologies to construct characterized source models for strong ground-motion simulations of the 1891 Nobi earthquake, which was a multi-segment rupture event occurring in the Nobi active-fault system. We evaluate the constructed source models by comparing the seismic intensities obtained from simulated waveforms with those estimated from the questionnaire-based intensities determined by Muramatu and Kominami (1992). The characterized source model constrained by seismological scaling relationships can give a more adequate distribution of the estimated seismic intensities. We also suggest that the Gifu-Ichinomiya fault might be considered as a source fault to explain the damage distribution on the Nobi Plain.
\end{abstract}

Key words: Multi-segment rupture event, source-model construction methodology, seismological scaling relationship, cascade model, 1891 Nobi earthquake.

\section{Introduction}

One of the most important issues in applied seismology is the establishment of a methodology for strong groundmotion prediction. The construction of a source model that can treat a variety of earthquake scenarios is the key for achieving reliable strong ground-motion prediction. A characterized source model (Irikura and Miyake, 2001) has recently been used as a source model for strong groundmotion prediction for scenario earthquakes (e.g., Iwata and Miyake, 2004; the Headquarters for Earthquake Research Promotion, 2005). Irikura and Miyake (2001) suggested a methodology for constructing the characterized source model based on the empirical relationships of the total rupture area and the combined asperity area with the seismic moment.

To develop a methodology for the construction of the characterized source model, it is essential to simulate the strong ground motion of actual earthquakes using such a model and to compare the results with the observation records. For example, the Headquarters for Earthquake Research Promotion (HERP) (2002, 2008a) has been con-

Copyright (C) The Society of Geomagnetism and Earth, Planetary and Space Sciences (SGEPSS); The Seismological Society of Japan; The Volcanological Society of Japan; The Geodetic Society of Japan; The Japanese Society for Planetary Sciences; TERRAPUB.

doi:10.5047/eps.2010.12.005 tinuously validating methods by comparing observed and synthetic strong ground motions and seismic intensities for, e.g., the 2000 Western Tottori Prefecture earthquake $\left(M_{\mathrm{J}} 7.3\right)$ and the 2005 West Off Fukuoka Prefecture earthquake $\left(M_{\mathrm{J}} 7.0\right)$. However, the source-fault lengths of those events are short and a validation of a multi-segment rupture event in a long active-fault zone has not yet been carried out.

For multi-segment ruptures, researchers have discussed whether or not the repetition of the same dislocation rupture characterizes each of the segments of a long active-fault zone (e.g., Sieh, 1996; McGill and Rubin, 1999; Kaneda and Okada, 2008). The repetition of the same dislocation rupture for each segment is not considered in existing construction methodologies for the characterized source model for strong ground-motion prediction, such as the methodology developed by HERP (2008b). However, several activefault studies have supported the concept of repetition of a similar slip along a segment (e.g., Sieh et al., 1996; Kondo et al., 2005). Therefore, in the construction methodology we need to consider the behavior of each segment involved in a multi-segment rupture. Here, we consider behavioral segments that are bounded by changes in the slip rates, recurrence intervals, elapsed times, sense of displacement, creeping versus locked behavior, and fault complexity (McCalpin, 1996). 
For the 1891 Nobi earthquake $(M$ 8.0) in Japan, the results of field investigations (e.g., Matsuda, 1974) and paleoseismological studies (e.g., Awata et al., 1999; Yoshioka et al., 2001) indicated that three behavioral segments ruptured along the Nukumi fault, the Neodani fault, and the Umehara fault. This means that the 1891 Nobi earthquake was a multi-segment rupture event. Although all the waveform records in the source region were clipped, seismic intensities based on the responses to a questionnaire survey are available at more than 1000 sites for estimating the strong ground-motion distribution.

In this study, we consider alternative construction methodologies for the characterized source model based on scaling from the entire rupture length and from behavioral segment lengths. We give multiple characterized source models for the 1891 Nobi earthquake as an example of a multi-segment rupture event. We compare the estimated seismic intensities from ground motions simulated by the characterized source models and those estimated from the questionnaire-based intensities determined by Muramatu and Kominami (1992). We also discuss the preferred construction methodology for the characterized source model for strong ground-motion prediction in a multi-segment rupture event.

Researchers have discussed the rupture of the GifuIchinomiya fault, which did not show clear evidence on surface faulting, in the 1891 Nobi earthquake (e.g., Muramatu, 1963; Mikumo and Ando, 1976; Aichi Prefecture, 1998, 2000; HERP, 2001; Fukuyama et al., 2007; Nakano et al., 2007). Based on the results of the strong ground-motion simulations, we also evaluate whether predictions using synthesis have the resolution to say whether or not the GifuIchinomiya fault ruptured during the 1891 earthquake.

\section{Previous Studies of the $\mathbf{1 8 9 1}$ Nobi Earthquake}

The Nobi earthquake, one of the greatest inland crustal earthquakes in Japan in recent times, occurred on October 28,1891 . It generated surface earthquake faulting along the active faults known as the Nukumi fault, the Neodani fault, and the Umehara fault (Fig. 1). Matsuda (1974) compiled field investigation reports (e.g., Koto, 1893; Omori, 1894; Bessho, 1967) and investigated traces of the surface earthquake faults and the distribution of displacements along these faults.

Trench studies have been done at the Nukumi (Yoshioka et al., 2001), Neodani (Miyakoshi et al., 1988; Kumamoto et al., 1992; Sato et al., 1992; Awata et al., 1999), and Umehara (Okada et al., 1992; Awata et al., 1999) faults to find the timings of paleofaulting and the recurrence interval of each fault. Awata et al. (1999) revealed that the Neodani fault has an average recurrence interval of 2,700 years whereas that of the Umehara fault is more than 11,000 years. Given the difference in the estimated average recurrence intervals, they concluded that the Neodani and Umehara faults are each a single behavioral segment. Yoshioka et al. (2001) excavated a trench in the Nukumi area and dated four recent faulting events of the Nukumi fault. By comparing the dates of faulting events on the Nukumi fault and the dates revealed by Awata et al. (1999) of faulting events on the Neodani fault, they showed that the

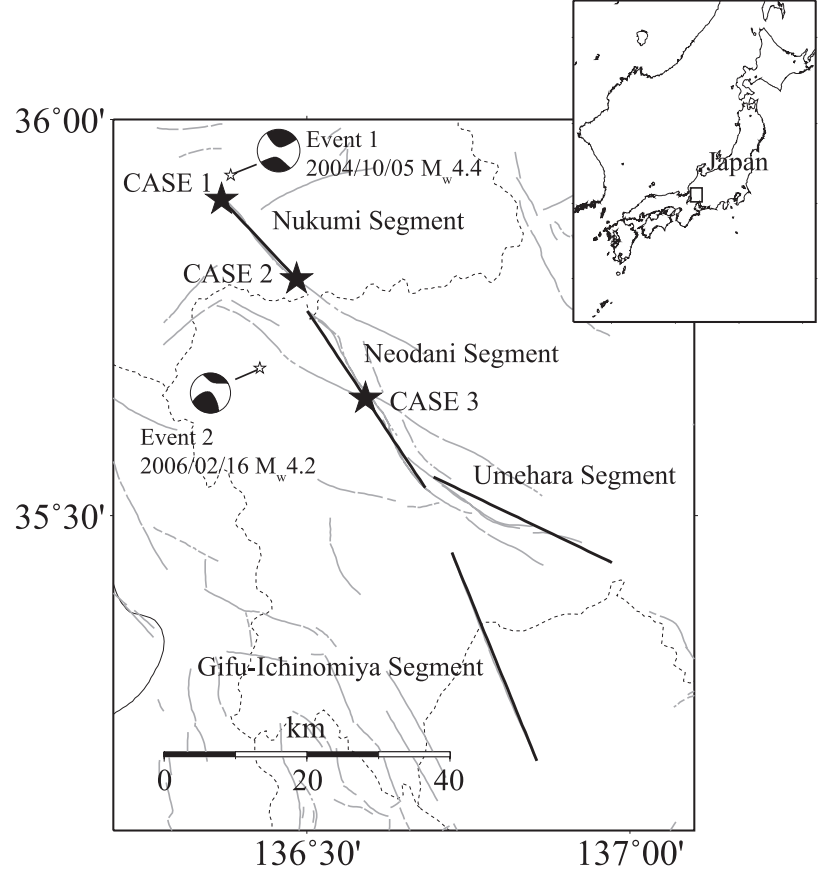

Fig. 1. Location of Nukumi, Neodani, Umehara, and Gifu-Ichinomiya segments assumed in this study (solid black line). Thin solid lines show location of active faults (Research Group for Active Faults of Japan, 1991). The three large stars indicate assumed rupture starting points. Epicenters (small stars) and focal mechanisms of small earthquakes are also shown.

two faults have not always ruptured simultaneously. According to the results of these paleoseismological studies, we can regard each of the Nukumi, Neodani, and Umehara faults as single behavioral segments. Therefore, the 1891 Nobi earthquake is considered to be a multi-segment rupture with at least three behavioral segments.

Kaneda and Okada (2008) performed detailed tectonic geomorphological mapping along the Neodani fault to test the behavioral model for a fault involved in a multi-segment rupture. They showed that the distributions of the leftlateral and vertical slip rates based on the estimated ages of terrace abandonment and the cumulative displacements of geomorphic markers mimic in shape those of left-lateral and vertical slips during the 1891 Nobi earthquake. They also indicated that the cumulative displacement since the L1 abandonment at $17-20 \mathrm{ka}$ is only three times the displacement of the 1891 event. This means that the recurrence interval from their slip-rate analysis is longer than that revealed by trench study at the Neodani fault. They concluded that if the recurrence interval revealed by Awata et al. (1999) for the Neodani fault is correct, this fault should not be characterized by repetition of the same slip-function earthquake ruptures or the characteristic slip-function behavior. However, they also noted that characteristic spatial slip-function behavior may still be expected if some of the identified faulting events are minor slip events caused by adjacent faults such as the Ibigawa and Mugigawa faults. In this study, via the validation of our construction methodology, we discuss whether or not the same slips were repeated on each behavioral segment.

Mikumo and Ando (1976) calculated theoretical verti- 
cal displacements based on the plural fault plane models of the 1891 Nobi earthquake and compared them with the observed vertical displacements along two leveling routes across the Umehara and Gifu-Ichinomiya faults. They indicated that movements of four faults including the GifuIchinomiya fault were needed to explain the observation. Nakano et al. (2007) determined the location and geometry of the Gifu-Ichinomiya fault by a grid-search method based on an inversion of the coseismic vertical displacements obtained by leveling surveys. They showed that the Gifu-Ichinomiya fault is located $5 \mathrm{~km}$ east of the location assumed in the model of Mikumo and Ando (1976). Fukuyama et al. (2007) evaluated the seismic moment of the 1891 earthquake by comparing calculated synthetic seismograms from a point source and finite source models with the historical seismogram recorded at the Central Meteorological Observatory in Tokyo. They showed that a comparison between the observed and synthetic seismograms appears to favor the existence of a buried fault along the Gifu-Ichinomiya line. In contrast to these results, the Aichi Prefecture $(1998,2000)$ and HERP (2001) used stratigraphic and seismic reflection surveys to rule out the possibility of the existence of the Gifu-Ichinomiya fault. We use the intensities estimated by Muramatu and Kominami (1992) to investigate whether the Gifu-Ichinomiya fault ruptured during the 1891 Nobi earthquake.

\section{Characterized Source Model for Strong-motion Prediction}

In the last section, we introduced the surface source fault and the distribution of the questionnaire-based seismic intensity of the Nobi earthquake for evaluating source models. We need to see how much it is possible to constrain the source model from the seismic intensity distribution. Kanda and Takemura (2005) developed source inversion using seismic intensity data. They estimated the empirical attenuation relation of the seismic intensity from recent earthquake data and applied it to the seismic intensity distribution of historical events by assuming that the finite source model consists of distributed point sources. They obtained spatial heterogeneity of source on the fault. Although their method gave information on the heterogeneity of the seismic wave radiation, our aim is to discuss the construction methodology of a seismic source model for multi-segment rupture events. Therefore, our approach is to construct a set of source models for ground-motion simulation, to estimate the ground motions according to those models, and to compare the observed and simulated seismic intensities in order to select the most appropriate model.

The characterized source model is one of the most reliable approaches for broadband strong ground-motion prediction. This model was proposed by Irikura and Miyake (2001). They first introduced a methodology for the source model construction. HERP applied this technique to explain the observations of recent disastrous earthquake events and confirmed the applicability and limitations of the method. Irikura et al. (2002) improved the method, and HERP summarized the methodology together with evaluation methods for the ground-motion simulation. This is now known as Irikura's recipe. The procedure and parameter settings are given in the Appendix.

For strong ground-motion simulation, we use the empirical Green's function (EGF) method proposed by Irikura (1986). Records of small events at the K-NET and KiK-net stations are used for the EGF. We simulate the ground motions for the Nobi earthquake at the strong motion recording sites, and estimate the seismic intensities from the simulation results.

\section{Strong Ground-motion Simulation \\ 4.1 Construction of characterized source models}

We construct characterized source models for strong ground-motion prediction using the procedure of HERP (2008b) and Irikura and Miyake (2010). Due to uncertainties that will be discussed, we eventually construct 24 models, listed in Table 1. We assume a multi-segment rupture of the northwestern part of the Nukumi fault (Nukumi segment), the Neodani fault (Neodani segment), and the Umehara fault (Umehara segment), along which surface earthquake faults appear (Fig. 1). We also consider a multisegment rupture including the Gifu-Ichinomiya fault (GifuIchinomiya segment). These four segments are assumed to be left-lateral strike-slip faults with a rake of 0 degrees. We obtain the location and rupture length of each segment from the traces of surface earthquake faults investigated by Matsuda (1974), except for the Gifu-Ichinomiya segment. Table 2 lists the lengths assumed here for each segment.

The Research Group for Active Faults of Japan (1991) estimated the location and length of the Gifu-Ichinomiya fault based on the boundary between tectonic uplift and subsidence. Sugisaki and Shibata (1961) suggested the existence of the Gifu-Ichinomiya fault from the vertical offset of a pumice bed of $5 \mathrm{~m}$ in the borehole records at Ichinomiya city. Fukuwa et al. (2003) estimated the locations of structural boundaries of the Nobi plain using the vertical gradient distribution of gravity anomaly. From their results, it seems that a structural boundary exists near the location of the Gifu-Ichinomiya fault shown by the Research Group for Active Faults of Japan (1991). Therefore, we use the location and length of the Gifu-Ichinomiya fault from the Research Group for Active Faults of Japan (1991). In Table 2, the length of the Gifu-Ichinomiya fault is listed.

We assume the width of each fault from the lower cutoff depth of microseismic activities, the depth of the upper limit of the fault plane, and the dip angle assumed for each fault. We assume that the depth of the lower limit of the fault plane of each fault is same as the bottom depth of the seismogenic zone. By referring to Ito (1999), we determine the bottom depth of the zone from the distribution of the hypocenters of the small earthquakes that occurred from 1926 to 2006 around the Nobi fault zone. These hypocenters were determined by the Japan Meteorological Agency (JMA).

For inland crustal earthquakes, HERP (2008b) has assumed that the depth of the upper limit of the fault plane is equal to the top depth of the seismogenic zone. In this case, the upper limit of the fault plane of the characterized source model does not reach the ground surface even if surface earthquake faults are generated during a scenario earthquake. However, some studies on source-fault rupture mod- 
Table 1. 24 characterized source models.

\begin{tabular}{|c|c|c|c|c|c|c|}
\hline Model & $\begin{array}{l}\text { Number of } \\
\text { segments }\end{array}$ & $\begin{array}{c}\text { Method to } \\
\text { obtain total } \\
\text { seismic moment }\end{array}$ & $\begin{array}{l}\text { Method to } \\
\text { obtain combined } \\
\text { asperity area }\end{array}$ & Epicenter & $\begin{array}{l}\text { Sum of squared } \\
\text { differences of } \\
\text { seismic intensity }\end{array}$ & Note \\
\hline 1 & \multirow{12}{*}{3} & \multirow{6}{*}{ total-L model } & \multirow{3}{*}{ Method1 } & $\begin{array}{c}\text { CASE1 } \\
\text { NW of } \\
\text { Nukumi segment }\end{array}$ & 51.9 & \\
\hline 2 & & & & $\begin{array}{c}\text { CASE2 } \\
\text { NE of } \\
\text { Nukumi segment }\end{array}$ & 51.1 & \\
\hline 3 & & & & $\begin{array}{c}\text { CASE3 } \\
\text { Middle of } \\
\text { Neodani segment }\end{array}$ & 46.7 & \\
\hline 4 & & & \multirow{3}{*}{ Method2 } & CASE1 & 34.1 & Fig. 10(d) \\
\hline 5 & & & & CASE2 & 33.4 & \\
\hline 6 & & & & CASE3 & 33.3 & \\
\hline 7 & & \multirow{6}{*}{ segment-L model } & \multirow{3}{*}{ Method1 } & CASE1 & 65.6 & \\
\hline 8 & & & & CASE2 & 66.3 & \\
\hline 9 & & & & CASE3 & 65.9 & \\
\hline 10 & & & \multirow{3}{*}{ Method2 } & CASE1 & 67.7 & \\
\hline 11 & & & & CASE2 & 67.3 & \\
\hline 12 & & & & CASE3 & 66.8 & \\
\hline 13 & \multirow{12}{*}{4} & \multirow{6}{*}{ total-L model } & \multirow{3}{*}{ Method1 } & CASE1 & 45.4 & Fig. 10(b) \\
\hline 14 & & & & CASE2 & 44.4 & \\
\hline 15 & & & & CASE3 & 46.0 & \\
\hline 16 & & & \multirow{3}{*}{ Method2 } & CASE1 & 27.2 & $\begin{array}{l}\text { Fig. } 8 \text {, Fig. } 10 \text { (a) } \\
\text { the most proper }\end{array}$ \\
\hline 17 & & & & CASE2 & 27.7 & \\
\hline 18 & & & & CASE3 & 29.5 & \\
\hline 19 & & \multirow{6}{*}{ segment-L model } & \multirow{3}{*}{ Method1 } & CASE1 & 57.8 & \\
\hline 20 & & & & CASE2 & 59.1 & \\
\hline 21 & & & & CASE3 & 62.6 & \\
\hline 22 & & & \multirow{3}{*}{ Method2 } & CASE1 & 67.0 & Fig. 10(c) \\
\hline 23 & & & & CASE2 & 67.3 & \\
\hline 24 & & & & CASE3 & 71.2 & \\
\hline
\end{tabular}

Table 2. Fault parameters for each segment.

\begin{tabular}{|c|c|c|c|c|}
\hline & Nukumi & Neodani & Umehara & Gifu-Ichinomiya \\
\hline Strike (degree) & 137 & 146 & 116 & 158 \\
\hline Dip (degree) & 90 & 90 & 90 & 90 \\
\hline Rake (degree) & 0 & 0 & 0 & 0 \\
\hline Rupture length $(\mathrm{km})$ & 16.7 & 29.8 & 27.8 & 31.6 \\
\hline Rupture width $(\mathrm{km})$ & 12.0 & 15.0 & 16.0 & 10.0 \\
\hline Rupture area $\left(\mathrm{km}^{2}\right)$ & 200 & 447 & 445 & 316 \\
\hline
\end{tabular}

els give a finite source model in which the fault plane reach the ground surface, e.g., Horikawa et al. (1996) for the 1995 Hyogo-ken Nanbu earthquake along the Nojima fault, and Wald and Heaton (1994) for the 1992 Landers earthquake. Their source models show slips in the shallower part of the fault plane at the surface earthquake faults. Since during the Nobi earthquake surface earthquake faults were generated along the Nukumi, Neodani, and Umehara faults, we assume that the depths of the upper limits of the fault planes are $0 \mathrm{~km}$. We also assume that all stations at the ground surface have a depth of $0 \mathrm{~km}$. Because no surface earthquake fault was generated along the Gifu-Ichinomiya fault, we assume that the depth of the upper limit of the GifuIchinomiya segment is equal to the top depth of the seismogenic zone. The dip angles of all segments are assumed to be 90 degrees. The width of each fault is listed in Table 2 .
We obtain two types of total seismic moments using two different methods (Fig. 2). In the first method which we call the total-L model ( $\mathrm{t}-\mathrm{L}$ model), we obtain the total seismic moment from the total rupture area by applying the empirical relationship given in Eq. (A.1). The total seismic moment is divided into the seismic moment for each segment under the condition that the static stress drops, which are obtained by applying the formula for a circular fault of Eshelby (1957), are the same among all segments. In this method, the average slip of each segment depends on the combination and number of segments that rupture simultaneously because for fixed width the seismic moment increases faster than the fault length.

In the second method which we call the segment-L model (s-L model), the seismic moment of each segment is obtained from the rupture area of that segment by applying 
total-L model

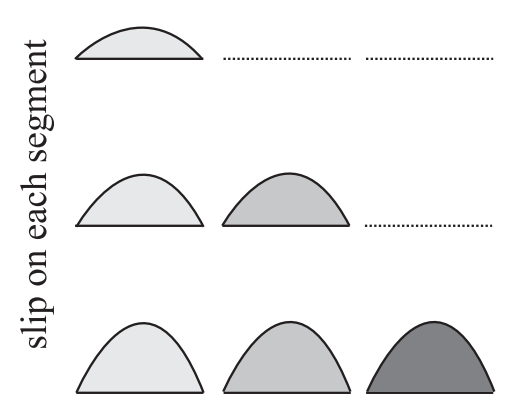

segment-L model

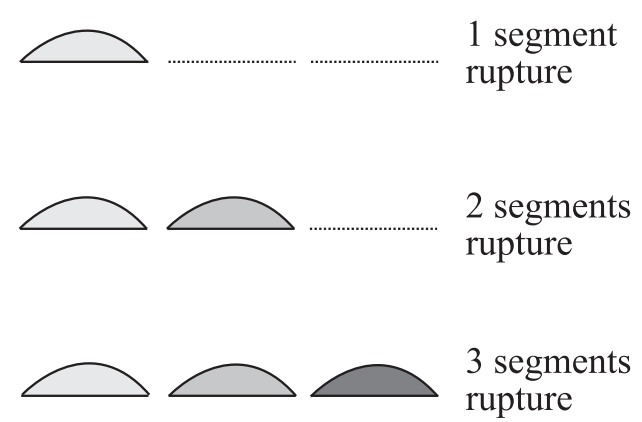

Fig. 2. Two different models used for obtaining total seismic moment. In total-L model, the average slip of each segment depends on the combination and number of ruptured segments. In segment-L model, the average slip of each segment is constant for any combination and number.

the empirical relationship in Eqs. (A.1) and (A.2). Here, we assume that this relationship between seismic moment and rupture area is satisfied for each behavioral segment. In this method, the average slip of each segment is constant for any combination and number of segments that rupture simultaneously. The total seismic moment is obtained by summing the seismic moments for each segment. This approach is based on the cascade model proposed by the Working Group on California Earthquake Probabilities (1995). The cascade model indicates that a behavioral segment ruptures independently or along with other contiguous segments and assumes that repetition of the same slip at given point characterizes the behavioral segment. The average slip of each segment increases as the rupture length increases when the downdip width of the fault reaches saturation because of the finite thickness of the brittle zone.

Applying the first method gives a total seismic moment of $6.64 \mathrm{E}+19 \mathrm{~N} \mathrm{~m}\left(M_{\mathrm{w}} 7.2\right)$ for a three-segment rupture and $1.10 \mathrm{E}+20 \mathrm{~N} \mathrm{~m}\left(M_{\mathrm{w}} 7.3\right)$ for a four-segment rupture. Applying the second method gives a total seismic moment of $2.48 \mathrm{E}+19 \mathrm{~N} \mathrm{~m}\left(M_{\mathrm{w}} 6.9\right)$ for a three-segment rupture and $3.04 \mathrm{E}+19 \mathrm{~N} \mathrm{~m}\left(M_{\mathrm{w}} 6.9\right)$ for a four-segment rupture (Fig. 3).

Next, we set up the combined asperity area using two different methods. In the first method (method 1), short-period spectral level of acceleration source spectrum, which is obtained from a seismic moment by applying the empirical relationship in Eq. (A.3), is used to estimate the equivalent radius of asperity. We apply the short-period spectral level of the acceleration source spectrum for causative faults to estimate the equivalent asperity radius in the total-L model. In the segment-L model, we assume the short-period spectral level of the acceleration source spectrum for each segment to estimate the equivalent asperity radius for that segment. In the other method (method 2), we use the relationship that for inland crustal earthquakes the combined asperity area is specified to be about $22 \%$ of the total rupture area (Somerville et al., 1999).

Table 3 lists the four models obtained by combining the two methods for obtaining the total seismic moment and the two methods for estimating the combined asperity area. In the t-L and t-L 22 models, we calculate the stress drop on asperity by applying Eq. (A.5) to the equivalent radius of the combined asperity area with $R$ being the equivalent

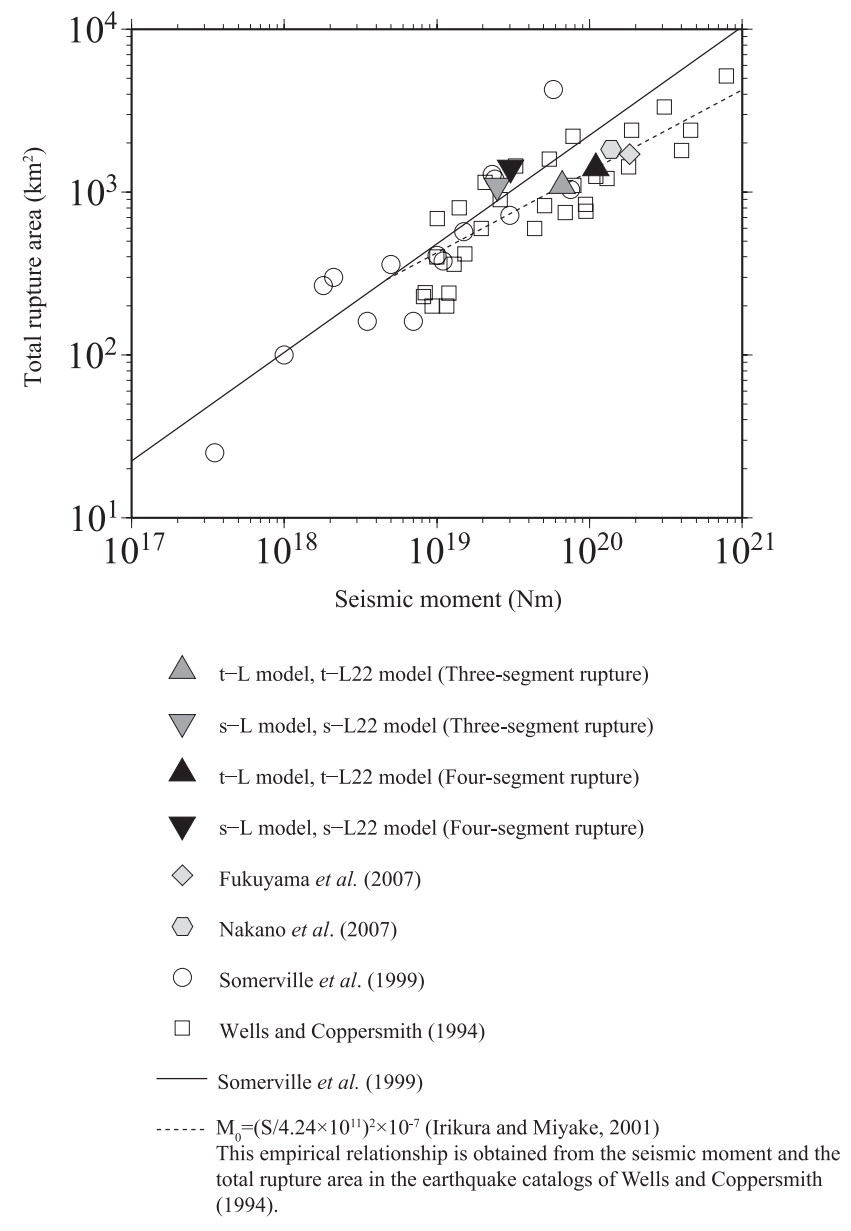

Fig. 3. Empirical relationship between seismic moment and total rupture area.

radius of the source fault area. In the s-L and s-L 22 models, we apply Eq. (A.5) to the equivalent radius of the asperity of each segment, with $R$ being the equivalent radius of the corresponding fault area. The stress drop on asperity in each model is listed in Table 4. We also estimate the effective stress on the background area of each segment using the method of HERP (2008b).

Sugiyama et al. (2002) revealed that the distributions of coseismic displacements along surface earthquake faults are consistent with the slip distributions in the shallower part of 
Table 3. Four models obtained by combining two methods for finding total seismic moment and two methods for estimating combined asperity area.

\begin{tabular}{|c|c|c|c|}
\hline & & \multicolumn{2}{|c|}{ Total seismic moment } \\
\hline & & $\begin{array}{l}\text { Applying the empirical } \\
\text { relationship to total } \\
\text { rupture area }\end{array}$ & $\begin{array}{l}\text { Applying the empirical } \\
\text { relationship to rupture } \\
\text { area of each segment }\end{array}$ \\
\hline \multirow{2}{*}{ Combined asperity area } & $\begin{array}{l}\text { The equivalent radius of asperity is obtained } \\
\text { from the short-period level of the acceleration } \\
\text { source spectrum by referring to Boatwright (1998) } \\
\text { and Dan et al. (2001). }\end{array}$ & $\begin{array}{l}\text { total- } \mathrm{L} \text { model } \\
(\mathrm{t}-\mathrm{L} \text { model })\end{array}$ & $\begin{array}{l}\text { segment-L model } \\
\quad(\mathrm{s}-\mathrm{L} \text { model })\end{array}$ \\
\hline & $\begin{array}{l}\text { Combined asperity area is specified to be } 22 \% \text { of } \\
\text { the total rupture area of the causative faults } \\
\text { (Somerville } \text { et al., 1999). }\end{array}$ & $\begin{array}{l}\text { total- } \mathrm{L} \& 22 \% \\
\text { asperity model } \\
(\mathrm{t}-\mathrm{L} 22 \text { model })\end{array}$ & $\begin{array}{l}\text { segment-L \& } 22 \% \\
\text { asperity model } \\
\text { (s-L22 model) }\end{array}$ \\
\hline
\end{tabular}

Table 4. Fault parameters for assumed characterized source models.

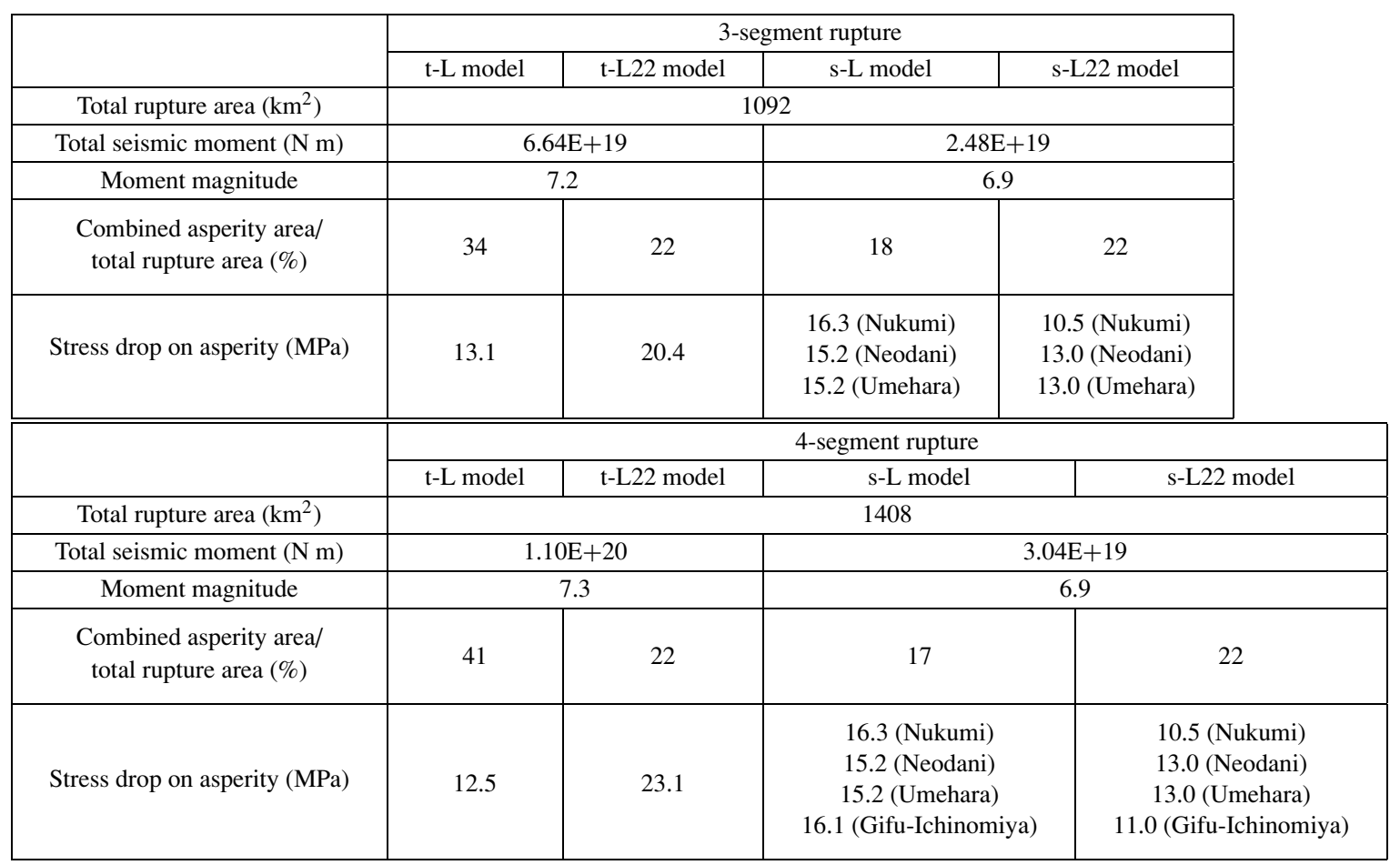

the seismic fault plane. Iwaki et al. (2006) identified the asperities on the fault plane for fourteen earthquakes and examined the spatial relationship between surface earthquake faults and subjacent source faults. They showed that locations where the surface displacements are large correspond in many cases to the locations of asperities on source faults. We assume that the asperities are located where larger dislocations are observed by referring to the distribution (Matsuda, 1974) of the left-lateral displacements.

We assume three rupture starting points (CASEs). The starting points of CASE1, CASE2, and CASE3 are located at the northwestern end of the Nukumi segment, the southeastern end of the Nukumi segment, and the middle section of the Neodani fault, respectively (Fig. 1). The locations for CASE1 and CASE3 are chosen by referring to Nakata et al. (1998) who gave a relation between the branching geometry of active faults and the location of a rupture starting point. The location for CASE2 is determined by referring to Muramatu et al. (2002) who suggested that the rupture started from a compression barrier caused by the geometry of the Nukumi and Neodani faults. We assume that the rupture starts from a deeper part of the fault plane by referring to HERP (2008b). We determine the depths of the starting points for CASE1, CASE2, and CASE3 to be $11.6 \mathrm{~km}$, $11.6 \mathrm{~km}$, and $12.6 \mathrm{~km}$, respectively. Based on Geller (1976), the rupture propagates radially with an average velocity that is $72 \%$ of the shear wave velocity in the source area, where the shear wave velocity is assumed to be $3.46 \mathrm{~km} / \mathrm{s}$ (e.g., HERP, 2004). Except for the segment where the rupture starts, segments rupture from the point that is nearest to the edge of the contiguous segment with almost the same depth as that of the rupture starting point. Different rupture starting times among the segments are provided by considering the rupture propagation in the segment fault and the propagation of the shear wave in the gap between the segment faults. We construct 24 characterized source models by combining the two methods for obtaining the total seismic moment, two methods for estimating the combined as- 
(a) Three-segment rupture

Nukumi

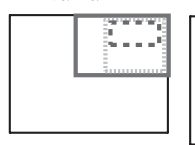

Umehara

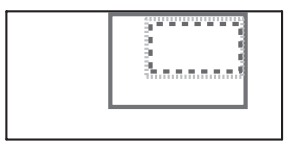

(b) Four-segment rupture
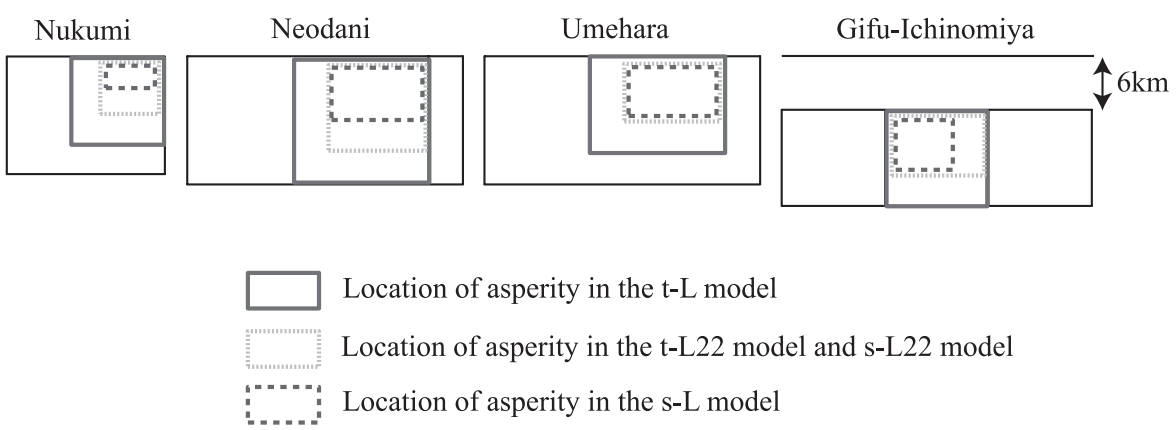

Fig. 4. Assumed characterized source models for 1891 Nobi earthquake. (a) Assumed characterized source models when three segments rupture (excluding Gifu-Ichinomiya fault). (b) Assumed characterized source models when four segments rupture (including Gifu-Ichinomiya fault). Rectangles show the location of asperity in each characterized source model.

perity area, three types of rupture starting points, and two cases of the multi-segment ruptures that includes or omits the Gifu-Ichinomiya segment (Fig. 4).

\subsection{Synthesis of strong ground motions}

We simulate strong ground motion using the EGF method proposed by Irikura (1986). This method has been used to simulate strong ground motions during inland crustal earthquakes such as the 1995 Hyogo-ken Nanbu earthquake (e.g., Kamae and Irikura, 1998) and the 2000 Tottori-ken Seibu earthquake (e.g., Ikeda et al., 2002). They used the recorded waveforms of aftershocks as the EGF to simulate the strong ground motions during the mainshock. In this study, we use the recorded waveforms of two small earthquakes that occurred around the Nobi fault zone to take into account the different propagation path from each segment to the strong motion stations (Fig. 1). We use the focal mechanism solutions of these small earthquakes determined by F-net (Fukuyama et al., 1998). Event 1 is an earthquake of $M_{\mathrm{w}} 4.4\left(M_{0}=4.86 \mathrm{E}+15 \mathrm{~N} \mathrm{~m}\right)$ in Fukui prefecture on October 5, 2004. Event 2 is an earthquake of $M_{\mathrm{w}} 4.2$ $\left(M_{0}=2.39 \mathrm{E}+15 \mathrm{~N} \mathrm{~m}\right)$ in Gifu prefecture on February 16,2006 . One nodal plane of the small earthquakes is almost consistent with that of the assumed fault plane. We use the recorded waveforms of Event 1 as the EGF for the Nukumi segment fault and those of Event 2 for the Neodani, Umehara, and Gifu-Ichinomiya segment faults.

We obtain $\log$ averages of the source displacement spectra with a hypocentral distance of $1 \mathrm{~km}$ using observed ground-motion records at four strong motion stations (FKIH01, FKIH04, GIFH09, GIFH22) that surround the hypocenters of the small earthquakes (Fig. 5), correcting propagation-path effect by $Q$ value of Satoh et al. (1994) and hypocentral distance. We determine corner frequencies of $2.0 \mathrm{~Hz}$ and $1.9 \mathrm{~Hz}$ for Event 1 and Event 2, respectively. We assume that the faults are circular cracks and estimate the radius $r_{\mathrm{c}}$ by referring to Brune $(1970,1971)$. The area of the fault for each event is calculated by $\pi r_{\mathrm{c}}^{2}$. We assume that subfaults of the large event are square-shaped so they are equivalent in area to the small-event fault. We therefore choose a subfault size of $1.1 \mathrm{~km}$ by $1.1 \mathrm{~km}$ for the Nukumi fault segment and $1.2 \mathrm{~km}$ by $1.2 \mathrm{~km}$ for the others. We calculate static stress drops of 8.0 $\mathrm{MPa}$ and 3.4 $\mathrm{MPa}$ for Event 1 and Event 2 respectively, by referring to Brune $(1970,1971)$. The rise time of each event is given from the empirical relationship between seismic moment and rise time given by Somerville et al. (1999).

In order to apply the EGF method, Eq. (1) should be satisfied for the seismic moment of the scenario earthquake $\left(M_{0}\right)$ and that of the small event $\left(m_{0}\right)$ :

$$
\frac{M_{0}}{m_{0}}=c \cdot N_{\mathrm{L}} \cdot N_{\mathrm{W}} \cdot N_{\mathrm{T}}
$$

On the right-hand side, $c$ is the ratio of the average stress drops, $N_{\mathrm{L}}$ is the number of subfaults along the fault length, $N_{\mathrm{W}}$ is the number of subfaults along the fault width, and $N_{\mathrm{T}}$ is the ratio of the rise times of the scenario earthquake and the small earthquake.

In our simulation, $N_{\mathrm{L}}, N_{\mathrm{W}}$, and $N_{\mathrm{T}}$ are more than 10 . Irikura and Kamae (1994) observed that the spectrum of the simulated ground motions has deeper sags in the intermediate frequency range as the number of summations for the EGF method increases. This is because of the effect of artificial enhancement of the recurrence period of the summation. To avoid these artificial sags, we introduce a twostage summation method to synthesize the waveforms. We first simulate ground motions for virtual middle-size earthquakes called Event 3 and Event 4 from the recorded waveforms of the real small earthquakes (Event 1 and Event 2). The fault sizes for Event 3 and Event 4 are $3.3 \mathrm{~km}$ by $3.3 \mathrm{~km}$ and $3.6 \mathrm{~km}$ by $3.6 \mathrm{~km}$, respectively. The seismic moments for Event 3 and Event 4 are $1.31 \mathrm{E}+17 \mathrm{~N} \mathrm{~m}$ and $6.45 \mathrm{E}+16 \mathrm{~N} \mathrm{~m}$, respectively. We assume that the rupture starting point is the center of the fault, and the stress drops of Events 3 and 4 are assumed to be the same as 
(a) Event 1
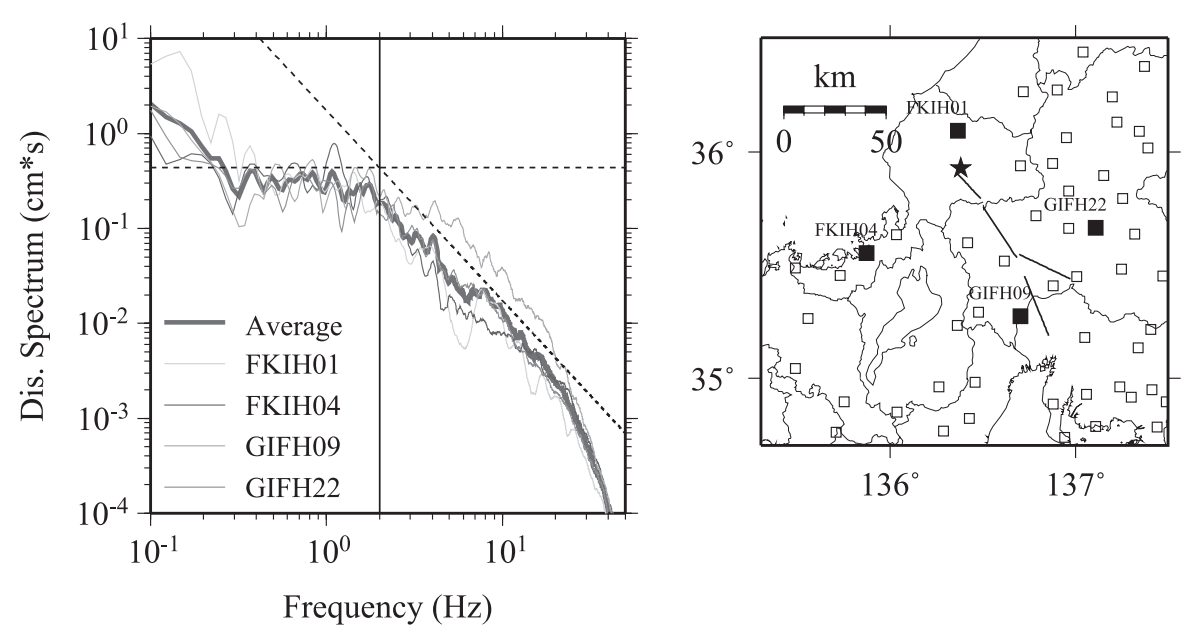

(b) Event 2
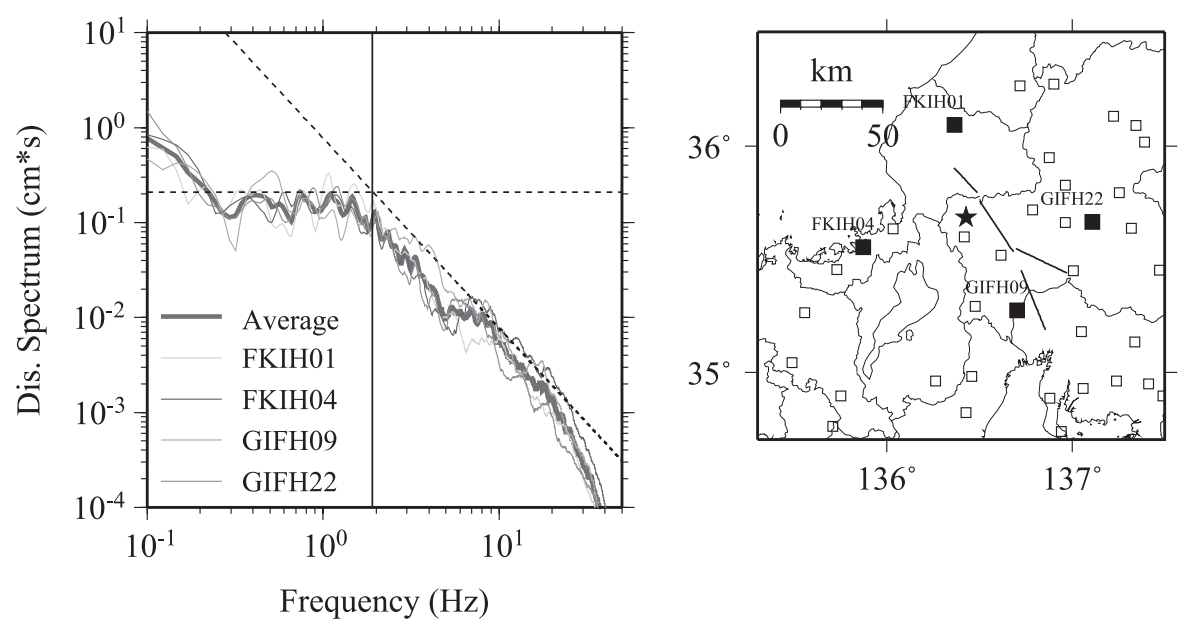

Fig. 5. (Left) Source displacement spectra with hypocentral distance of $1 \mathrm{~km}$ obtained from observed ground-motion records at four strong motion stations and log-averaged source displacement spectra among these stations. Source displacement spectra of Event 1 and Event 2, respectively, are shown in (a) and (b). Solid line in the left figure shows the corner frequency. (Right) Distribution map of strong motion stations around hypocenters of Event 1 and Event 2. Solid line in the right figure shows the location of assumed segments. Closed squares indicate the location of strong motion stations at which we calculate source displacement spectra.

those of Events 1 and 2, respectively. As a second step, we synthesize the waveforms of the Nobi earthquake using the simulated waveforms of the virtual middle-size earthquakes. Equation (1) is satisfied for the seismic moment of asperity area of each segment and that of the small event. It is also satisfied in background slip area of each segment. Parameters for the EGF method are listed in Table 5.

We simulate the acceleration and velocity waveforms of the NS, EW, and UD components at 148 strong motion stations of K-NET (Kinoshita, 1998) and KiK-net (Aoi et al., 2000). We use the recorded waveforms of the small earthquakes for $30 \mathrm{~s}$ from $0.5 \mathrm{~s}$ before the direct $S$-wave onset. The frequency band for simulating the acceleration and velocity waveforms is 0.5 to $10.0 \mathrm{~Hz}$. A cutoff frequency $f_{\max }$ of $6 \mathrm{~Hz}$ is chosen in this study (e.g., Satoh, 2002).

\section{Questionnaire-based Intensity Distribution of the 1891 Nobi Earthquake}

The Tokyo Imperial University conducted a nationwide questionnaire survey about one month after the 1891 Nobi earthquake. Muramatu and Kominami (1992) determined seismic intensities by relating the gathered information to the JMA intensity scales (Fig. 6(a)). They considered the change in the degree of earthquake protection of wooden houses by referring to the relationship between earthquake damage and seismic intensity for the 1923 Kanto earthquake.

We use the questionnaire-based intensities to estimate the seismic intensities at the strong motion stations. We assume that the questionnaire-based intensities are the same as the JMA intensity scales. The answers to the questionnaires seem to reflect the situations of the communities around the locations where the questionnaire survey was conducted. 


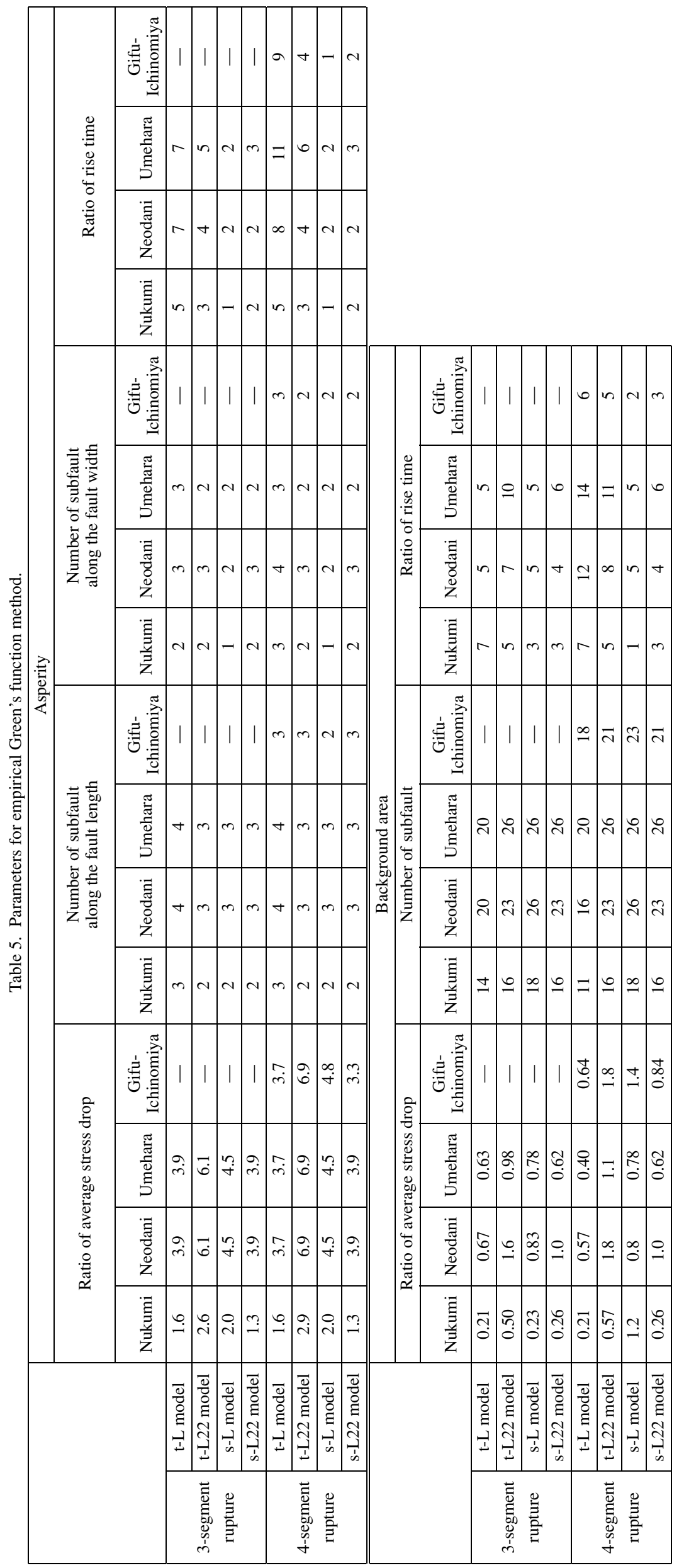


(a)

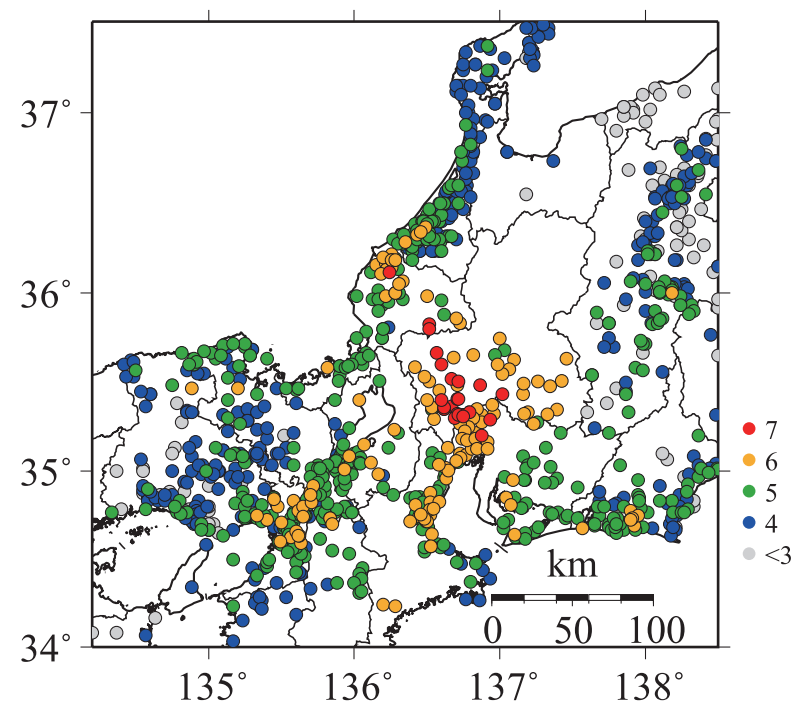

(b)

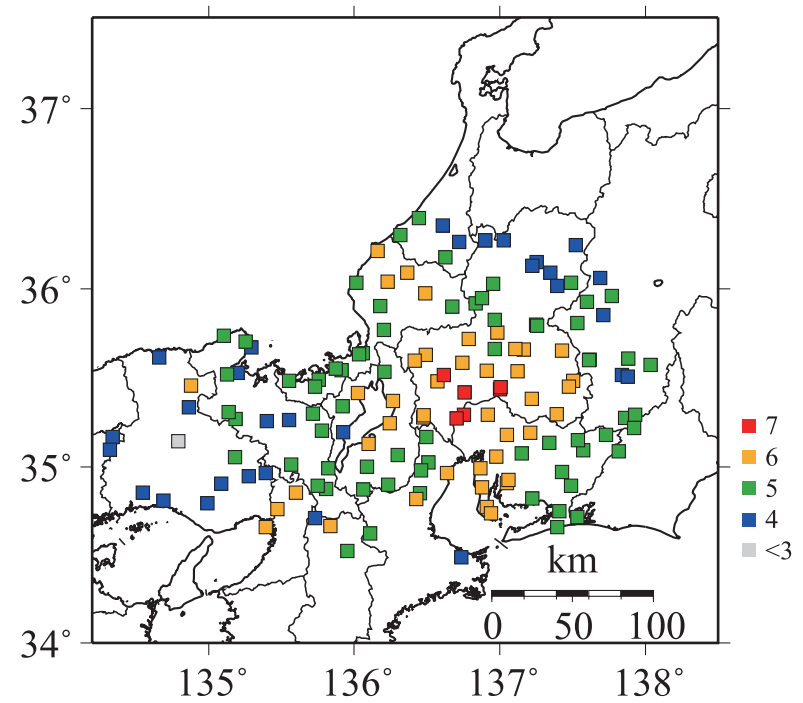

Fig. 6. (a) Distribution of questionnaire-based intensities estimated by Muramatu and Kominami (1992). (b) Distribution of estimated seismic intensity scales at strong motion stations from questionnaire-based intensities.

Therefore, we calculate the seismic intensities at the strong motion stations from the questionnaire-based intensities reported within $5 \mathrm{~km}$. We estimate the seismic intensities in units of 1 degree by applying the inverse distance weighted mean of the questionnaire-based intensities. If there are no questionnaire-based intensities within $5 \mathrm{~km}$ of a strong motion station, we estimate the seismic intensity by referring to the contour map of the distribution of the questionnairebased intensities determined by Muramatu and Kominami (1992).

The questionnaire-based intensity is estimated from the plural reports of degree of damages in a community. On the contrary, the obtained seismic intensity at a station shows the ground motion level at that station. This implies that the seismic intensity at the station might not be representa-
Estimation of seismic intensity scale (SIS $_{\mathbf{q i}}$ ) from questionnaire-based intensities determined by Muramatu and Kominami (1992)

\section{$\downarrow$}

Calculation of seismic intensity (SI $\mathbf{S a l}_{\mathbf{c a l}}$ ) at intervals of 0.1 degree and seismic intensity scale (SIS $\left.\mathbf{S}_{\mathbf{c a l}}\right)$ in units of 1 degree using simulated acceleration waveforms

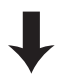

Comparison of SIS $_{\mathrm{cal}}$ and SIS $_{\mathrm{qi}}$ and calculation of difference(DIF.) of seismic intensities by following rules below at each station

(a) $\mathrm{SIS}_{\mathrm{cal}}=\mathrm{SIS}_{\mathrm{qi}} \quad$ DIF. $=0$

(b) SIS $_{\text {cal }} \neq$ SIS $_{\text {qi }}$

\begin{tabular}{|c|c|}
\hline $\mathrm{SIS}_{\mathrm{cal}}<\mathrm{SIS}_{\mathrm{qi}}$ & DIF. $=\left|\mathrm{SI}_{\text {cal }}-\mathrm{SI}_{\text {qi_low }}\right|$ \\
\hline $\mathrm{SIS}_{\mathrm{cal}}>\mathrm{SIS}_{\mathrm{qi}}$ & DIF. $=\mid \mathrm{SI}_{\mathrm{cal}}-\mathrm{SI}_{\mathrm{qi} \_ \text {high }}$ \\
\hline 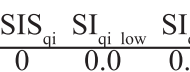 & 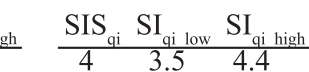 \\
\hline $0.5 \quad 1$ & $\begin{array}{lll}5 & 4.5 & 5.4\end{array}$ \\
\hline 1.5 & 5.5 \\
\hline 2.5 & 6.5 \\
\hline
\end{tabular}

Calculation of sum of squared DIF.

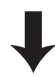

Examination of the most proper model by using the sum of squared DIF.

Fig. 7. Flowchart of procedure to evaluate assumed characterized source model using seismic intensities obtained from simulated waveforms with those estimated from questionnaire-based intensities.

tive of intensity in the community. In this study, we use the distribution of the questionnaire-based intensities and the estimated seismic intensities in many communities (Fig. 6). We could assume that the distribution of the estimated seismic intensities at the strong motion stations has the characteristics of that of the questionnaire-based intensities of the 1891 Nobi earthquake. We compare the seismic intensities calculated from the simulated waveforms of the assumed source models with those estimated based on the questionnaire. The procedure for choosing the best model is shown in detail in Fig. 7.

\section{Results}

The sum of the squared differences of the seismic intensities obtained from simulated waveforms and those estimated from the questionnaire-based intensities is the smallest in the characterized source model 16.

Figure 8(a) shows the distributions of the simulated seismic intensity scale values $\left(\mathrm{SIS}_{\mathrm{cal}}\right)$ for the model 16 . For 
(a)

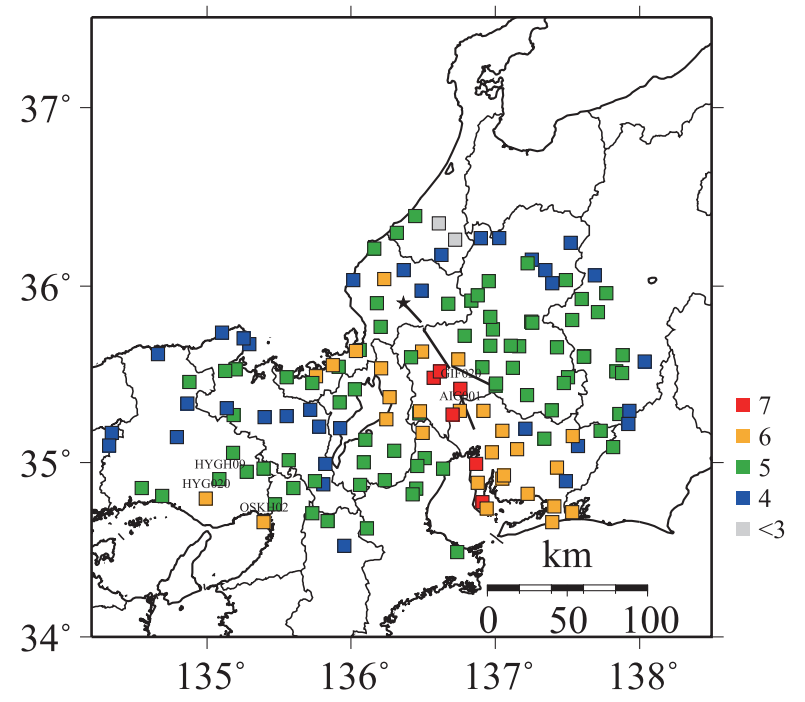

(b)

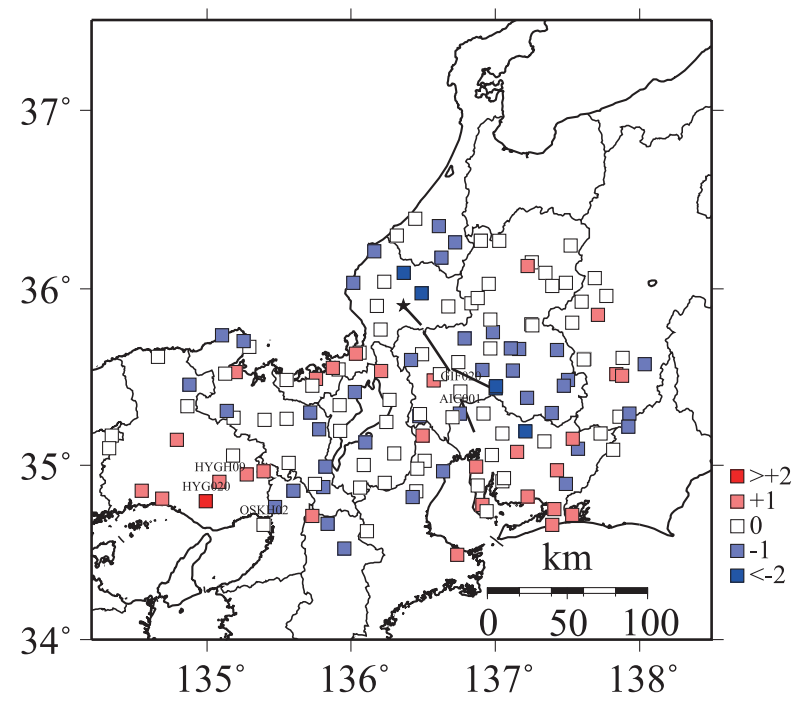

Fig. 8. (a) Distribution of simulated seismic intensity scales $\left(\mathrm{SIS}_{\mathrm{cal}}\right)$ in best characterized source model. (b) Distribution of differences between simulated seismic intensity scales $\left(\right.$ SIS $\left._{\mathrm{cal}}\right)$ and estimated questionnaire-based intensity scales $\left(\mathrm{SIS}_{\mathrm{qi}}\right)$ in best characterized source model. The difference is calculated by SIS $_{\mathrm{cal}}-\mathrm{SIS}_{\mathrm{qi}}$.

this model, SIS $_{\text {cal }}$ values above 6 are simulated at the KNET strong motion stations at AIC001 and GIF020 in the heavily damaged region with a wooden-house damage ratio from Muramatu (1983) of more than $80 \%$. Strong motion stations with SIS $_{\mathrm{cal}}$ values above 6 are distributed from the southwestern part of Gifu prefecture to Aichi prefecture. Figure 8(b) shows the distributions of the differences of the SIS $_{\text {cal }}$ values for model 16 and the estimated questionnairebased scale values $\left(\mathrm{SIS}_{\mathrm{qi}}\right)$. The $\mathrm{SIS}_{\mathrm{cal}}$ values are mostly within 1 of the SIS $_{\mathrm{qi}}$ values. At the strong motion stations in the heavily damaged region, the SIS $_{\mathrm{cal}}$ values are consistent with the SIS $_{\mathrm{qi}}$ values.

Figure 9 shows the simulated acceleration waveforms of the NS and EW components at the AIC001 and GIF020 stations located in the heavily damaged region. At GIF020, a peak ground acceleration of more than $3000 \mathrm{~cm} / \mathrm{s}^{2}$ is simulated. The seismic wave radiating from the Neodani segment causes this large acceleration.

Figure 10 shows the distributions of the differences between the SIS $_{\text {cal }}$ values and the SIS $S_{\mathrm{qi}}$ values for models 16 , 13, 22, and 4. The difference between the best model and the models assumed in Fig. 10(b), (c), and (d) is the method for estimating the combined asperity area, obtaining the total seismic moment, and deciding whether or not the GifuIchinomiya fault ruptured. The sums of the squared differences for the models in Fig. 10(a), (b), (c), and (d) are 27.2, 45.4, 67.0, and 34.1. We observe from Fig. 10(c) that the SIS $_{\text {cal }}$ values are significantly smaller than the SIS $_{\text {qi values }}$ at most strong motion stations. In Fig. 10(d), the SIS $_{\text {cal val- }}$ ues are inconsistent with the SIS $_{\mathrm{qi}}$ values at the strong motion stations in the heavily damaged region. This means that rupturing in the Gifu-Ichinomiya segment might be necessary to explain the distribution of the damage caused to wooden houses near the Gifu-Ichinomiya fault.

\section{Discussion}

7.1 Comparison of simulated peak horizontal velocities (PHVs) with empirical attenuation relationship

We compare the attenuation characteristics of the simulated peak horizontal ground velocities (PHVs) in the source model 16 with the empirical attenuation relation of Kanno et al. (2006). In this comparison, we use the attenuation relation of PHVs for soil with $V_{\mathrm{s}} 30$ of $300 \mathrm{~m} / \mathrm{s}$. An amplification correction toward this value is estimated by applying the $V_{\mathrm{s}} 30$ from the PS logging results of K-NET and $\mathrm{KiK}$-net to the empirical relationship of Midorikawa et al. (1994). The attenuation characteristics of the PHVs in the best characterized source model are found to approximately follow the empirical attenuation relation, as shown in Fig. 11. However, the PHVs at HYG020, HYGH09, and OSKH02 are larger than expected. These stations are located in the southwestern area more than $100 \mathrm{~km}$ from the causative faults. At these stations, the waveforms radiating from the Neodani and Gifu-Ichinomiya segments significantly affect the results of the strong ground-motion simulation. We used the recorded waveforms of Event 2 to simulate waveforms from the Neodani and Gifu-Ichinomiya segment faults. The PHVs of the recorded waveforms of Event 2 at HYG020, HYGH09, and OSKH02 are larger than the attenuation relation obtained from $\mathrm{PHV}$ at other stations. It seems that a propagation-path effect causes these larger-than-expected PHVs. Here, we confirmed that the selection of the best model is independent of whether these stations are included or not.

\subsection{Verification of the source model 16}

The characterized source model constrained by the seismological scaling relationship is better for expressing the distribution of the estimated seismic intensities. In this model, the total seismic moment is $1.10 \mathrm{E}+20 \mathrm{~N} \mathrm{~m}$. From the historical seismograms recorded at the Central Meteorological Observatory in Tokyo, Fukuyama et al. (2007) estimated the total seismic moment of the Nobi earthquake to be $1.83 \mathrm{E}+20 \mathrm{~N} \mathrm{~m}\left(M_{\mathrm{w}}=7.5\right)$. Based on an inversion analysis of the coseismic vertical displacements, 
AIC001 NS component

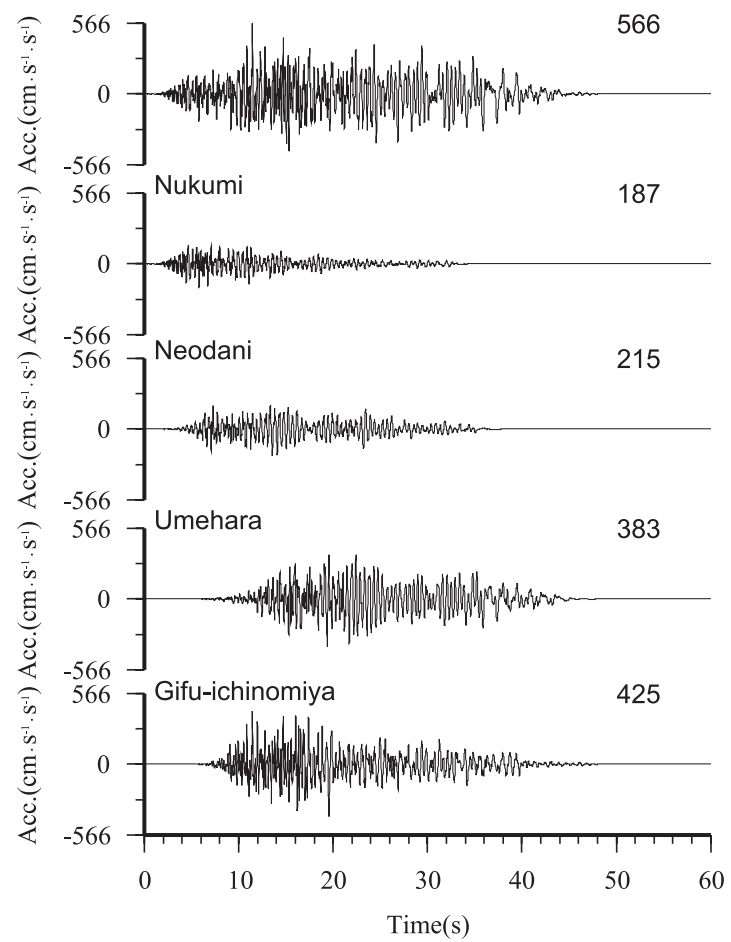

GIF020 NS component

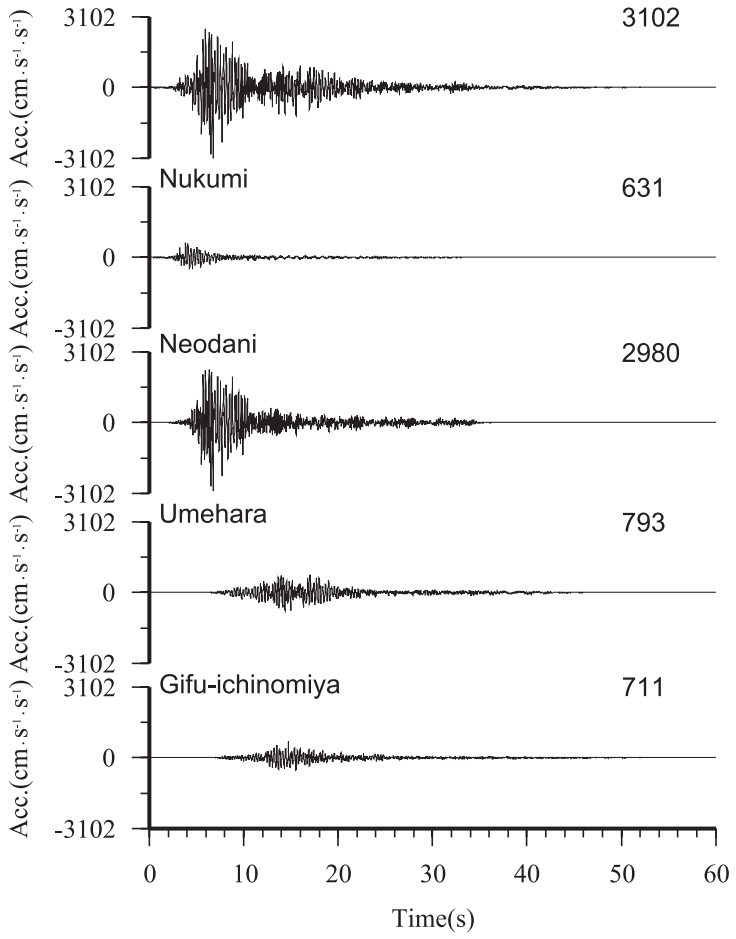

AIC001 EW component

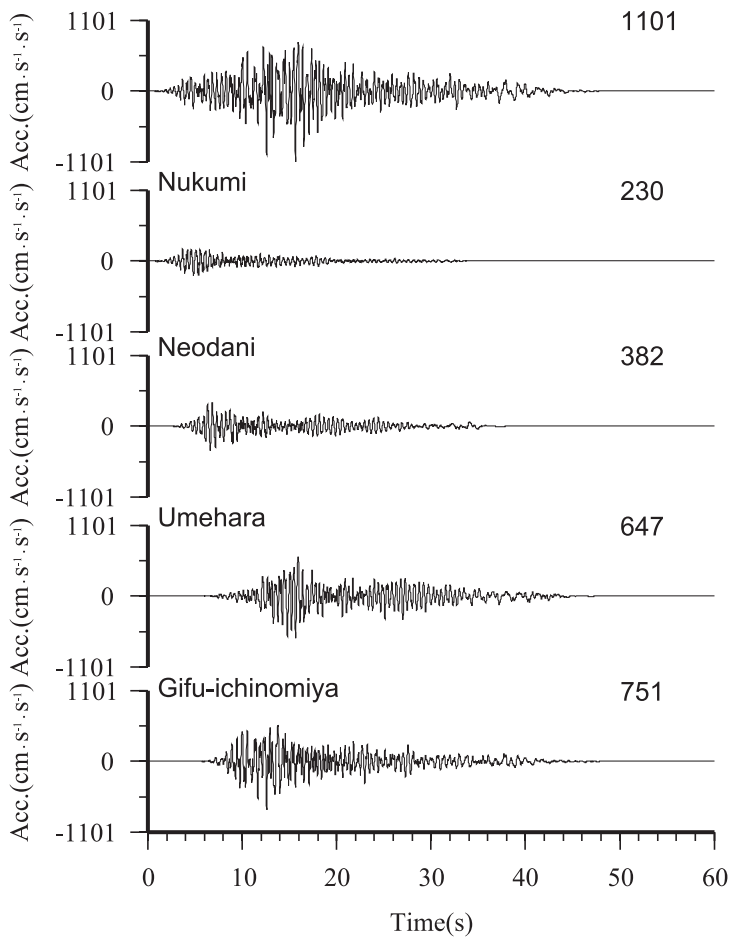

GIF020 EW component

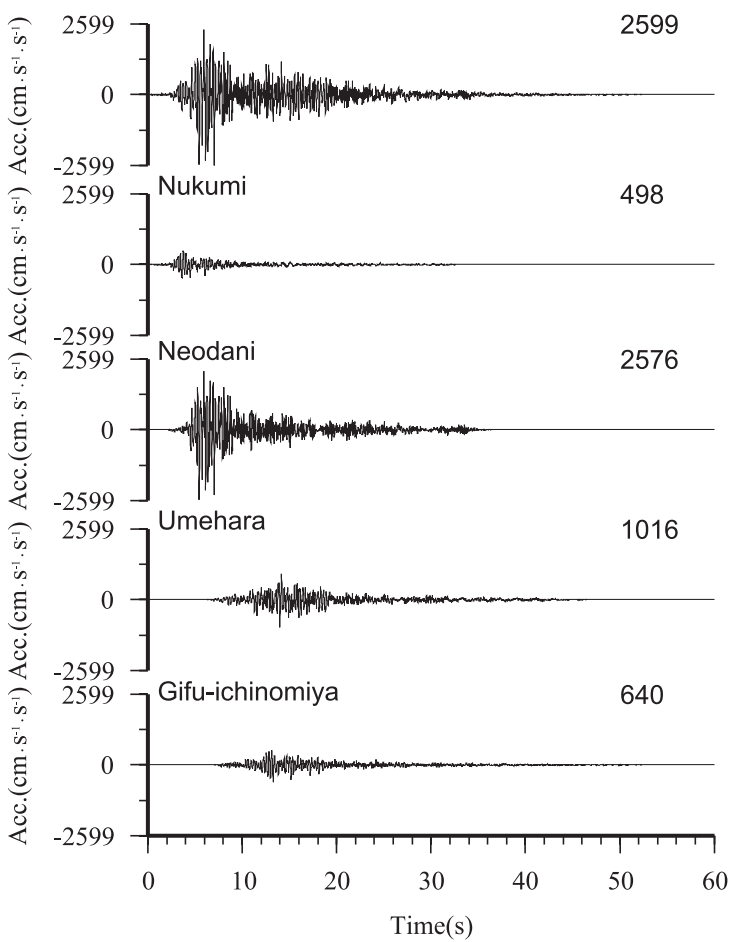

Fig. 9. Simulated acceleration waveforms of NS and EW components at AIC001 and GIF020. Values indicate peak accelerations of simulated waveforms.

Nakano et al. (2007) estimated the total seismic moment to be $1.38 \mathrm{E}+20 \mathrm{~N} \mathrm{~m}\left(M_{\mathrm{w}}=7.4\right)$. These two values are slightly larger than the total seismic moment of the source model 16 .
The seismic moments of each behavioral segment in the model 16 are larger than those obtained by applying the empirical relationship to the rupture area of the segment. If the empirical relationship between seismic moment and 
(a) t-L22 model,CASE 1, 4 segments

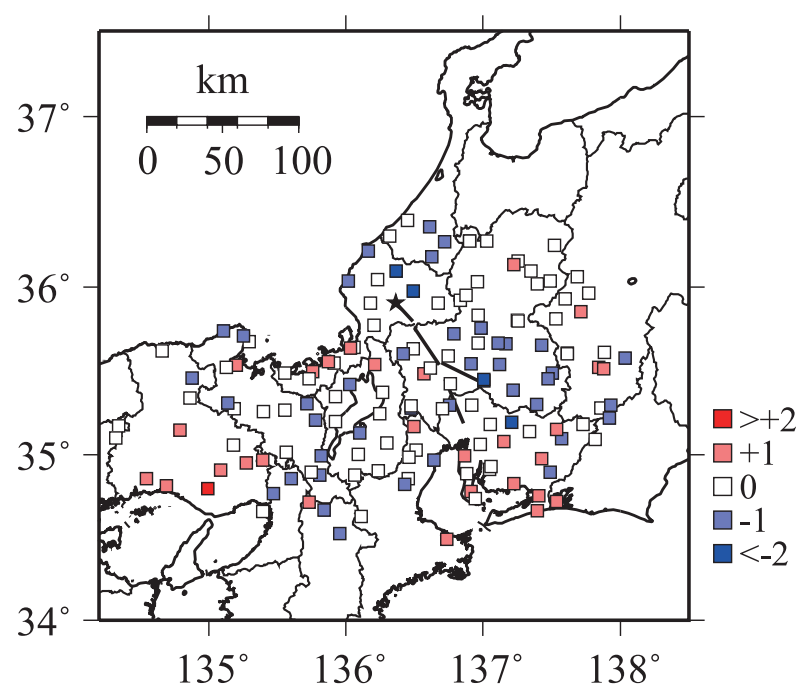

(c) s-L22 model,CASE 1, 4 segments

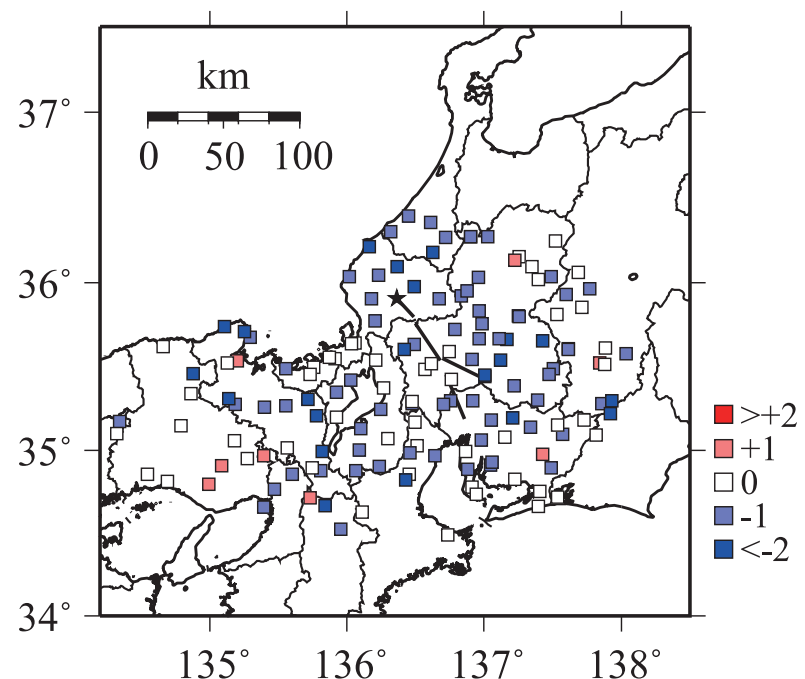

(b) t-L model,CASE 1, 4 segments

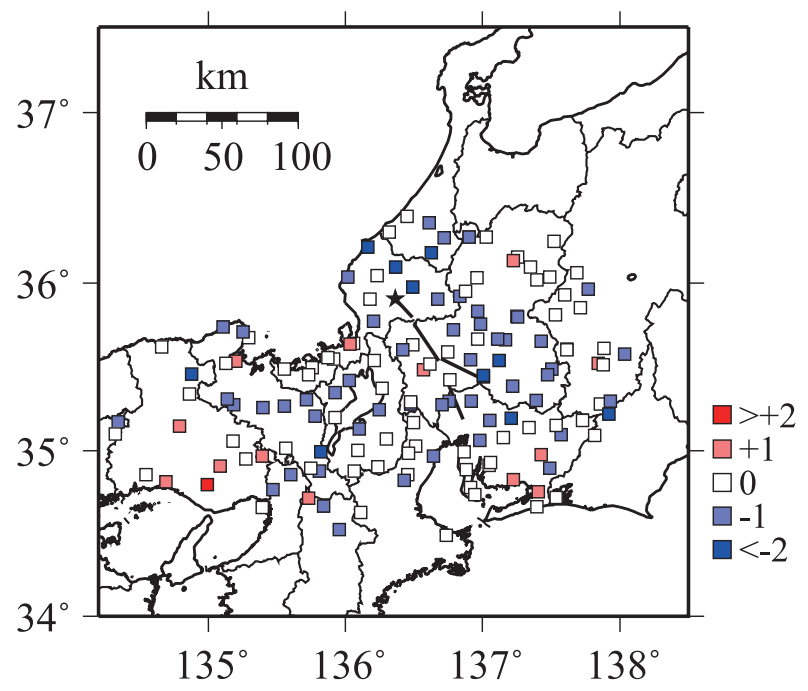

(d) t-L22 model,CASE 1, 3 segments

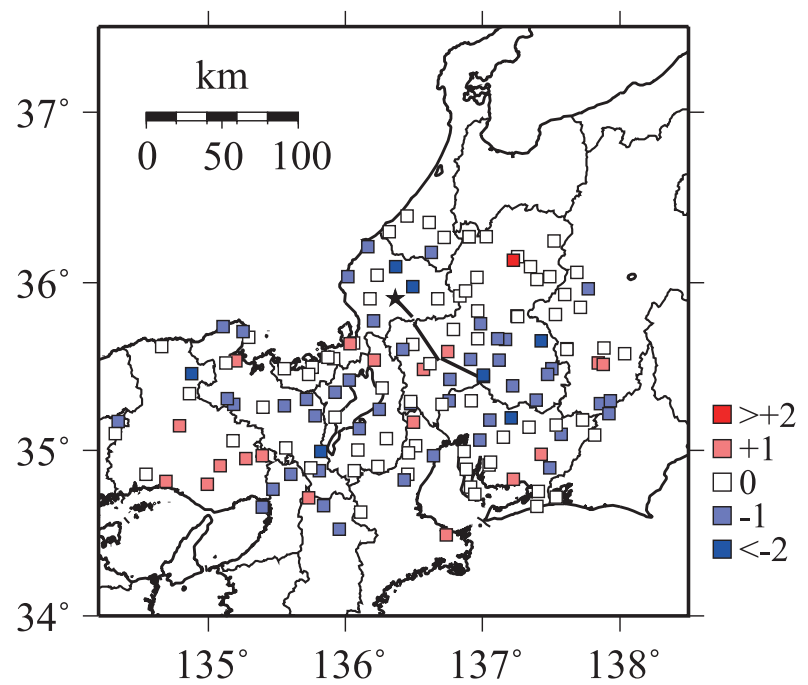

Fig. 10. Distributions of differences between simulated seismic intensity scales ( SIS $_{\text {cal }}$ ) and estimated questionnaire-based intensity scales (SIS $\left.\mathrm{Si}_{\mathrm{q}}\right)$. (a) t-L22 model case1, rupturing Gifu-Ichinomiya segment, (b) t-L model case1, rupturing Gifu-Ichinomiya segment, (c) s-L22 model case1, rupturing Gifu-Ichinomiya segment, (d) t-L22 model case1, not rupturing Gifu-Ichinomiya segment.

rupture area is satisfied for each behavioral segment in a single-segment rupture, our result may mean that the slip of each segment in a multi-segment rupture is different from that in a single-segment rupture.

Kaneda and Okada (2008) observed that if the earthquake recurrence interval estimated from a previous paleoseismic trench is correct, the tectonic geomorphological observations in the Neodani fault can be explained by repetition of a similarly shaped slip distribution independently of the rupture of adjacent faults, but with a variable amount of slip. Our result appears to be consistent with their result in that it has no repetition of the same dislocation rupture for the Neodani segment.

Wesnousky (2008) examined the average and maximum values of the coseismic slip as a function of the surface rupture length. Wesnousky considered the slopes of the fitted curves describing the slip increase and found that these slopes decrease as a function of the total rupture length without apparently reaching a plateau in the strikeslip earthquake data. If the relationship between the slip of a behavioral segment and the total rupture length is similar, the difference of the slip in a single-segment rupture and that in a multi-segment rupture may be small, and similar displacements may be repeated along the segment with a large rupture length. In the Nobi fault zone, the rupture length of each segment may not be enough to satisfy this relationship.

We assume that the combined asperity area is specified to be about $22 \%$ of the total rupture area in source model 16 . In this model, the stress drops on asperity are $23.1 \mathrm{MPa}$ for all segments. Dan et al. (2005) discussed two methods for estimating the effective stress on asperity for inland earth- 


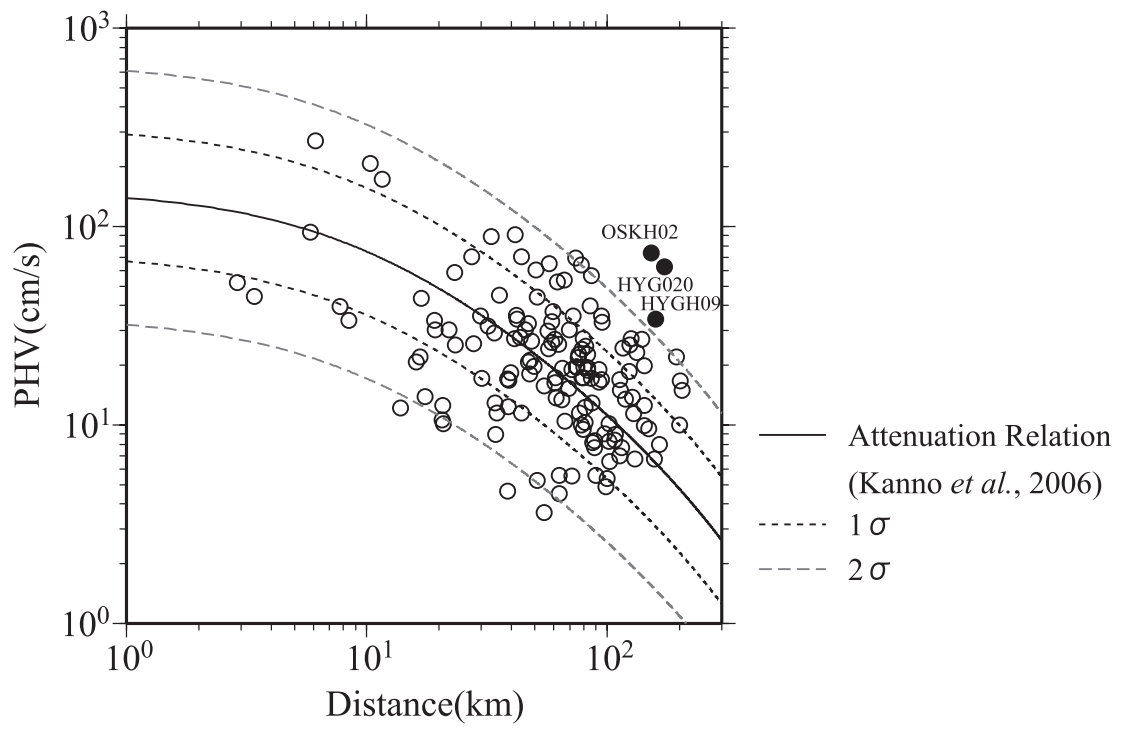

Fig. 11. Attenuation characteristics of PHVs for soil with $V_{\mathrm{s}} 30$ of $300 \mathrm{~m} / \mathrm{s}$ in best characterized source model.

quakes caused by large strike-slip faults. The first method is based on the scaling law of Irikura and Miyake (2001) and the crack model. In the second method, the effective stress on asperity is $14.1 \mathrm{MPa}$ independent of the earthquake size. Following Madariaga (1979), in the second method the effective stress on asperity of 14.1 MPa is estimated from the average static stress drop (e.g., 3.1 MPa from Fujii and Matsu'ura (2000)) and the ratio of the combined asperity area to the total rupture area. Dan et al. (2005) conducted strong ground-motion simulations based on characterized source models with different values for the effective stress on asperity. They compared simulated peak ground velocities with the attenuation relation of $\mathrm{Si}$ and Midorikawa (1999) and concluded that the effective stress on asperity from the second method is more proper. In this study, the attenuation characteristics of the simulated peak ground velocity in the source model 16 are found to approximately follow the empirical attenuation relation. This shows that the calculated stress drop on asperity of the model 16 is preferred for the Nobi earthquake.

The location of the rupture starting point in the model 16 is the northwestern end of the Nukumi segment (CASE1). However, the sum of the squared differences of seismic intensity is almost the same for CASE1 and CASE2 (southeastern end of the Nukumi segment). By comparing synthetic seismograms with recorded seismograms at the Gifu and Nagoya stations, Mikumo and Ando (1976) estimated the location of the starting point to be the northwestern end of the Nukumi fault. Muramatu et al. (2002) also estimated the starting point to be the northwestern end of the Nukumi fault based on the time interval reported by Matsuda (1974) of about $10 \mathrm{~s}$ to the formation of the surface fault at Seki. Our result is consistent with these previous results.

Our results show that the Gifu-Ichinomiya fault might rupture during the Nobi earthquake. The location of the Gifu-Ichinomiya segment in this study is based on that of the Research Group for Active Faults of Japan (1991). The location is nearer Nagoya City than that used by Mikumo and Ando (1976). We also assume the dip of the Gifu-
Ichinomiya segment to be 90 degrees. Mikumo and Ando (1976) assumed a buried fault with a dip of 90 degrees. Nakano et al. (2007) estimated a thrust fault with a dip of 60 degrees located $5 \mathrm{~km}$ east of the location of Mikumo and Ando (1976). They compared the distribution of seismic intensities calculated using their best model with the distribution from Muramatu (1983) of the damage caused to wooden houses by the Nobi earthquake. However, they did not calculate seismic intensities of 7 at Gifu city where the percentage of damaged houses is more than $80 \%$. In the model 16, we simulate a seismic intensity of 7 at Gifu city. The distribution of the strong motion stations showing a seismic intensity above 6 near the Gifu-Ichinomiya fault might be consistent with the distribution from Muramatu (1983) of the damage caused to wooden houses.

\section{Conclusions}

We examine the source-model construction methodology for the strong ground-motion prediction of scenario earthquakes in a long active-fault zone including a multi-segment rupture case. We construct 24 characterized source models of the 1891 Nobi earthquake by combining two methods for obtaining the total seismic moment, two methods for estimating the combined asperity area, three types of rupture starting points, and two cases of the multi-segment ruptures that includes or omits the Gifu-Ichinomiya segment. We conduct strong ground-motion simulation for the characterized source models using the empirical Green's function method.

To determine the most plausible source-model construction methodology, we compare the seismic intensities calculated from simulated waveforms using the assumed source models with those estimated from the questionnairebased intensities determined by Muramatu and Kominami (1992). The sum of the squared differences between the seismic intensities obtained from simulated waveforms and those estimated from the questionnaire-based intensities is the smallest in the source model having the following characteristics: (1) the total seismic moment is given by ap- 
plying the methodology based on seismological scaling relationships, (2) the combined asperity area is specified to be $22 \%$ of the total rupture area (Somerville et al., 1999), (3) the rupture starting point is the northwestern end of the Nukumi segment, and (4) the Gifu-Ichinomiya fault might rupture during the 1891 Nobi earthquake.

The attenuation characteristics of the PHVs in the best characterized source model are found to approximately follow the empirical attenuation relation of Kanno et al. (2006). In this model, the total seismic moment is $1.10 \mathrm{E}+20 \mathrm{~N} \mathrm{~m}\left(M_{\mathrm{w}} 7.3\right)$. The seismic moments of each behavioral segment in the best characterized source model are larger than those obtained by applying the empirical relationship to the rupture area of each segment. If the empirical relationship between seismic moment and rupture area is satisfied for each behavioral segment in a single-segment rupture, our result may imply that the slip of each segment in a multi-segment rupture is different from that in a singlesegment rupture.

Acknowledgments. We are grateful to two anonymous reviewers for the critical reviews and suggestions on the original manuscripts. We sincerely thank Prof. Takashi Kumamoto for helpful comments. We used data from the K-NET and KiK-net strong motion networks. We also used the moment tensor solutions of two small-sized events from the F-net. We are grateful to the National Research Institute for Earth Science and Disaster Prevention (NIED) for providing the K-NET, KiK-net, and F-net. We used hypocentral information provided by Japan Meteorological Agency (JMA). Some figures have been drawn using GMT (Wessel and Smith, 1998).

\section{Appendix A. A Procedure for Source Modeling for Strong Ground-motion Simula- tion: Brief Introduction of Irikura's Recipe}

Here, we describe the procedure for source model construction referring to Irikura's recipe (HERP, 2008b; Irikura and Miyake, 2010) for strong ground-motion simulation.

Irikura and Miyake (2001) have proposed a characterized source model for strong ground-motion prediction. It is based on an asperity model. The source fault consists of the asperity and the remaining area is called the background area. The total rupture area and the asperity area are given by the empirical relationships between total rupture area and seismic moment and between combined asperity area and seismic moment. Figure A.1 shows the resulting procedure for constructing a characterized source model (modified from HERP, 2008b). This model is characterized by outer fault parameters, inner fault parameters, and extra parameters.

The outer fault parameters are the total rupture area, total seismic moment, and average stress drop on the fault. The total seismic moment is found by applying the twostage scaling relationships between seismic moment and total rupture area. The empirical scaling relationship in Eq. (A.1) is obtained from the seismic moment and the total rupture area in the earthquake catalogs of Wells and Coppersmith (1994). It can be applied when $M_{0} \geq 7.5 \times$ $10^{18} \mathrm{~N} \mathrm{~m}$ (Irikura and Miyake, 2001). Equation (A.2) is obtained from the seismic moment and total rupture area of the slip models of 15 inland crustal earthquakes given by Somerville et al. (1999). It can be applied when $M_{0} \leq$ $7.5 \times 10^{18} \mathrm{~N} \mathrm{~m}$.

$$
\begin{aligned}
& M_{0}=\left(S / 4.24 \times 10^{11}\right)^{2} \times 10^{-7} \\
& M_{0}=\left(S / 2.23 \times 10^{15}\right)^{3 / 2} \times 10^{-7}
\end{aligned}
$$

where $S$ is the total rupture area in $\mathrm{km}^{2}$ and $M_{0}$ is the seismic moment in $\mathrm{N}$ m. In HERP (2008b), for multisegment ruptures, the total seismic moment is divided into the seismic moment for each segment under the condition that the average static stress drops are constant among all segments. In this method, the seismic moment and the average slip of each segment depend on the combination and number of segments that rupture simultaneously.

The average stress drop on the fault is obtained by applying the formula for a circular fault of Eshelby (1957) in a case of $S \propto M_{0}^{1 / 3}$ and by the formula on the tectonic loading stress (e.g. Fujii and Matsu'ura, 2000) in cases of $S \propto M_{0}^{1 / 2}$ or $S \propto M_{0}$. HERP (2008b) also describes that the average stress drop value obtained by the later formula is provisional and the applicability needs to be examined. Here, we apply the formula for a circular fault of Eshelby (1957) to obtain the average stress drop.

The inner fault parameters characterize heterogeneity inside the fault. These parameters are the combined asperity area, stress drop on asperity, number of asperities, average asperity slip, effective stress on asperity and background area, and slip-velocity time function. In HERP (2008b) and Irikura and Miyake (2010), two methods are suggested to give the combined asperity area. In the first method, a shortperiod spectral level of the acceleration source spectrum is used to obtain the equivalent asperity radius. This level is given by the empirical relationship in Eq. (A.3) between seismic moment and short-period spectral level (Dan et al., 2001).

$$
A=2.46 \times 10^{17} \times\left(M_{0} \times 10^{17}\right)^{1 / 3}
$$

where $A$ is the short-period spectral level of the acceleration source spectrum in $\mathrm{N} \cdot \mathrm{m} / \mathrm{s}^{2}$. The equivalent asperity radius can be obtained from Eq. (A.4) under the assumption of a circular crack. Equation (A.4) is obtained by referring to Boatwright (1988) and Dan et al. (2001).

$$
r=(7 \pi / 4) \cdot M_{0} /(A \cdot R) \cdot \beta^{2}
$$

In Eq. (A.4), $r$ is the equivalent asperity radius in $\mathrm{km}, R$ is the equivalent radius of the source faults in $\mathrm{km}$, and $\beta$ is the shear wave velocity in $\mathrm{km} / \mathrm{s}$. In the second method, the combined asperity area is given by an empirical relationship: for inland crustal earthquakes it is specified to be about $22 \%$ of the total rupture area (Somerville et al., 1999).

The static stress drop on asperity is estimated from Eq. (A.5) when a circular source fault can be assumed (Boatwright, 1988). Irikura's recipe also proposes a method for estimating the stress drop on asperity for long strike-slip faults using the average static stress drop.

$$
\Delta \sigma_{\mathrm{a}}=(7 / 16) \cdot M_{0} /\left(r^{2} \cdot R\right)=\Delta \sigma_{\mathrm{c}} \cdot\left(S / S_{\mathrm{a}}\right)
$$

In Eq. (A.5), $\Delta \sigma_{\mathrm{a}}$ is the static stress drop on asperity in $\mathrm{MPa}, \Delta \sigma_{\mathrm{c}}$ is the average stress drop on the fault in MPa, 


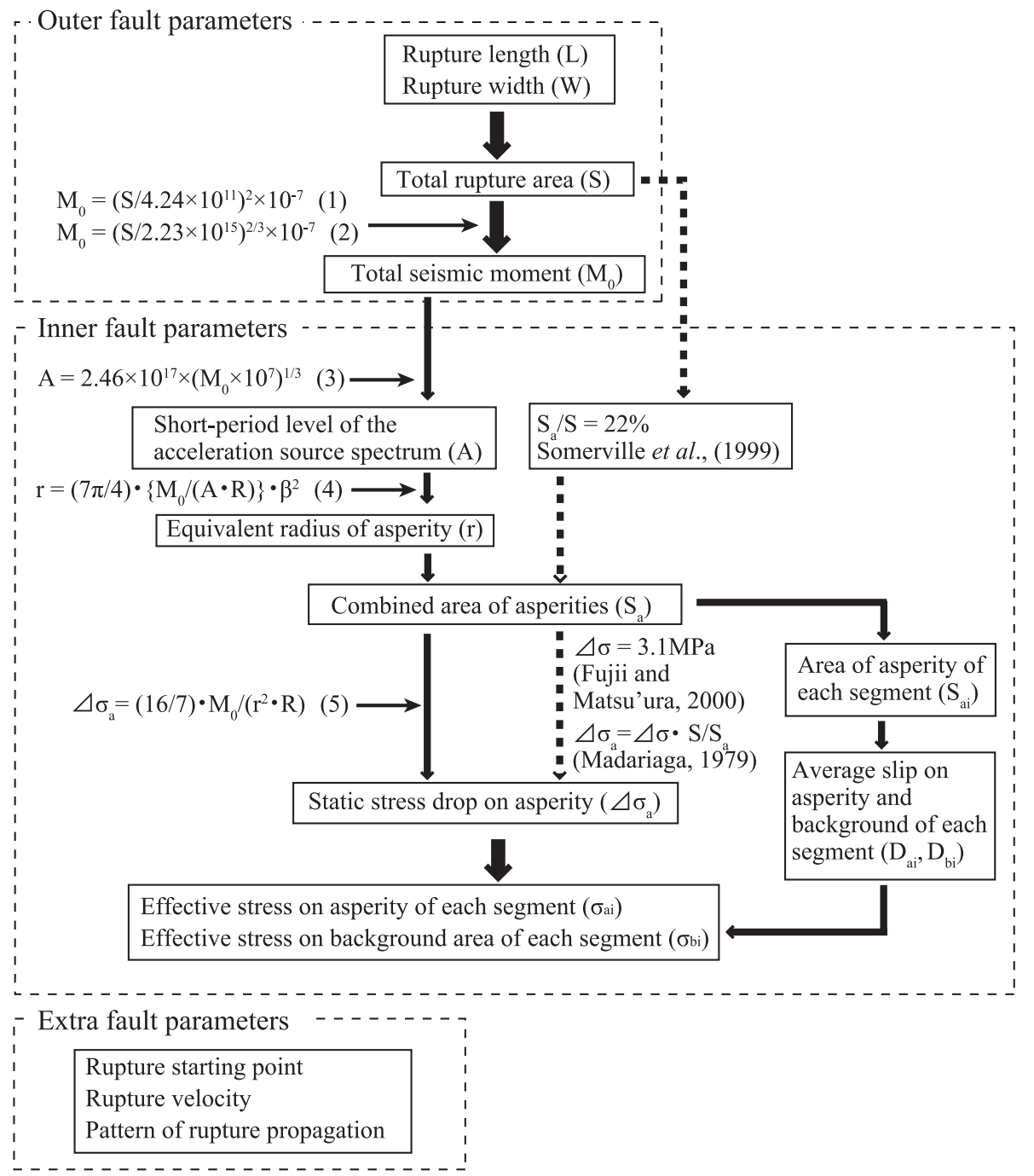

Fig. A.1. Flowchart of procedure to characterize fault parameters based on HERP recipe (modified from HERP, 2008b).

and $S_{\mathrm{a}}$ is the combined asperity area in $\mathrm{km}^{2}$. The stress drop on asperity is treated as the effective stress on asperity. In HERP (2008b), the effective stress on the background area is estimated from the stress drop on asperity, the widths of the asperities and the total area, and the average slips of asperity and background area by following Dan et al. (2002).

HERP (2008b) describes that a number of asperity in each segment is 1 or 2 by referring to the past studies (e.g. Somerville et al., 1999). The locations of the asperities are assumed by referring to the distribution of surface displacements measured along a fault. Irikura and Miyake (2010) also describes that the information on the back-slip rate found by GPS observations and the weak reflection coefficients in the fault plane is useful to assume the locations of the asperities. In HERP (2008b), average slip on asperities is twice the average slip on the fault based on Somerville et al. (1999) and Ishii et al. (2000). Meanwhile, Irikura and Miyake (2010) proposes that average slip on asperities is estimated by empirical relationship from quasi-dynamic simulation results of Dalguer et al. $(2004,2008)$.

The extra fault parameters are the rupture starting point, pattern of propagation of the rupture, and rupture velocity.
The candidate locations of rupture starting points can be estimated following Nakata et al. (1998) who gave a model of the relation between the branching geometry of active faults and the location of the rupture starting point.

\section{References}

Aichi Prefecture, Research Report of the Gifu-Ichinomiya and YoroKuwana-Yokkaichi Fault Zones, 118 pp, 1998 (in Japanese).

Aichi Prefecture, Underground Structure in the Nobi Plain, 61-70, 2000 (in Japanese).

Aoi, S., K. Obara, S. Hori, K. Kasahara, and Y. Okada, New strong-motion observation network, KiK-net, Eos Trans. AGU, 81, F863, 2000.

Awata, Y., Y. Kariya, and K. Okumura, Segmentation of the surface ruptures associated with the 1891 Nobi earthquake, Central Honshu, Japan, based on the paleoseismic investigations, Interim Report on Active Fault and Paleoearthquake Researches in the 1998 Fiscal Year, 115-130, 1999 (in Japanese with English abstract).

Bessho, B., Unusual tectonic movements, Rep. Geol., Kanazawa Univ., 1, 1-364, 1967 (in Japanese).

Boatwright, J., The seismic radiation from composite models of faulting, Bull. Seismol. Soc. Am., 78, 489-508, 1988.

Brune, J. N., Tectonic stress and the spectra of seismic shear waves from earthquakes, J. Geophys. Res., 75, 4997-5009, 1970.

Brune, J. N., Correction, J. Geophys. Res., 76, 5002, 1971.

Dalguer, L. A., H. Miyake, and K. Irikura, Characterization of dynamic asperity source models for simulating strong ground motions, Proceedings of the 13th World Conference on Earthquake Engineering, No. 3286 , 
2004.

Dalguer, L. A., H. Miyake, S. M. Day, and K. Irikura, Surface rupturing and buried dynamic-rupture models calibrated with statistical observations of past earthquakes, Bull. Seismol. Soc. Am., 98, 1147-1161, 2008.

Dan, K., M. Watanabe, T. Sato, and T. Ishii, Short-period source spectra inferred from variable-slip rupture models and modeling of earthquake faults for strong motion prediction by semi-empirical method, J. Struct. Constr. Eng., AIJ, 545, 51-62, 2001 (in Japanese with English abstract).

Dan, K., T. Sato, and K. Irikura, Characterizing source model for strong motion prediction based on asperity model, Proceedings of the Japan Earthquake Engineering Symposium, 555-560, 2002 (in Japanese with English abstract).

Dan, K., T. Muto, J. Miyakoshi, and M. Watanabe, Estimation of effective stress on asperities in inland earthquakes caused by large strike-slip faults and its application to strong motion simulation, J. Struct. Constr. Eng., AIJ, 589, 81-88, 2005 (in Japanese with English abstract).

Eshelby, J. D., The determination of the elastic field of an ellipsoidal inclusion, and related problems, Proc. R. Soc. Lond. Ser. A, 241, 376396, 1957

Fujii, Y. and M. Matsu'ura, Regional difference in scaling laws for large earthquakes and its tectonic implication, Pure Appl. Geophys., 157, 2283-2302, 2000.

Fukuyama, E., M. Ishida, D. S. Dreger, and H. Kawai, Automated seismic moment tensor determination by using on-line broadband seismic waveforms, Zisin, Second Ser., 5l, 149-156, 1998 (in Japanese with English abstract).

Fukuyama, E., I. Muramatu, and T. Mikumo, Seismic moment of the 1891 Nobi, Japan, earthquake estimated from historical seismograms, Earth Planets Space, 59, 553-559, 2007.

Fukuwa, N., K. Yamaoka, M. Nakano, J. Tobita, T. Sato, and Y. Suzuki, Investigation for the mechanism of the seismic damage band on Nobi earthquake, Report of Grants-in-Aid for Scientific Research (Research Project Number F12480110), 2003 (in Japanese).

Geller, R. J., Scaling relations for earthquake source parameters and magnitudes, Bull. Seismol. Soc. Am., 66, 1501-1523, 1976.

Horikawa, H., K. Hirahara, Y. Umeda, M. Hashimoto, and F. Kusano, Simultaneous inversion of geodetic and strong-motion data for the source process of the Hyogo-ken Nanbu, Japan, earthquake, J. Phys. Earth, 44, 455-471, 1996.

Ikeda, T., K. Kamae, S. Miwa, and K. Irikura, Source characterization and strong ground motion simulation of the 2000 Tottori-ken Seibu earthquake using the empirical Green's function method, J. Struct. Cosntr. Eng., AIJ, 561, 37-45, 2002 (in Japanese with English abstract).

Irikura, K., Prediction of strong acceleration motions using empirical Green's function, Proc. 7th Japan Earthq. Eng, 151-156, 1986.

Irikura, K. and K. Kamae, Estimation of strong ground motion in broadfrequency band based on a seismic source scaling model and an empirical Green's function technique, Ann. Geofis., 37, 1721-1743, 1994.

Irikura, $\mathrm{K}$. and $\mathrm{H}$. Miyake, Prediction of strong ground motions for scenario earthquakes, J. Geogr., 110(6), 849-875, 2001 (in Japanese with English abstract)

Irikura, K. and H. Miyake, Recipe for predicting strong ground motion from crustal earthquake scenarios, Pure Appl. Geophys., http://www. springerlink.com/content/424323g755p14436/fulltext.pdf, 2010.

Irikura, K., H. Miyake, T. Iwata, K. Kamae, and H. Kawabe, Revised recipe for predicting strong ground motion and its validation, 11th JEEE, 567572, 2002 (in Japanese with English abstract).

Ishii, T., T. Sato, and P. G. Somerville, Identification of main rupture areas of heterogeneous fault models for strong ground-motion estimation, $J$. Struct. Constr. Eng., AIJ, 527, 61-70, 2000 (in Japanese with English abstract).

Ito, K., Seismogenic layer, reflective lower crust, surface heat flow and large inland earthquakes, Tectonophysics, 306, 423-433, 1999.

Iwaki, H., H. Ito, N. Kitada, N. Inoue, T. Kagawa, K. Miyakoshi, K. Takemura, and A. Okada, Compiling the catalog of surface faults due to large earthquakes and subjacent source faults, Active Fault Res., 26, 37-61, 2006 (in Japanese with English abstract).

Iwata, T. and H. Miyake, Ground motion simulation during a scenario earthquake based on the strong motion prediction recipe-In case of the northern part of the Biwako-Seigan faults as a hypothetical source fault-, J. JSNDS, 23-2, 259-271, 2004 (in Japanese with English abstract).

Kamae, K. and K. Irikura, Source model of the 1995 Hyogo-ken Nanbu earthquake and simulation of near-source ground motion, Bull. Seismol. Soc. Am., 88, 400-412, 1998.

Kanda, K. and M. Takemura, Verification of the sequence of disastrous earthquakes off Miyagi prefecture based on seismic intensity data, Zisin Second Ser., 58, 177-198, 2005 (in Japanese with English abstract).

Kaneda, H. and A. Okada, Long-term seismic behavior of a fault involved in a multiple-fault rupture: Insights from tectonic geomorphology along the Neodani fault, central Japan, Bull. Seismol. Soc. Am., 98, 21702190, 2008.

Kanno, T., A. Narita, N. Morikawa, H. Fujiwara, and Y. Fukushima, A new attenuation relation for strong ground motion in Japan based on recorded data, Bull. Seismol. Soc. Am., 96, 879-897, 2006.

Kinoshita, S., Kyoshin Net (K-NET), Seismol. Res. Lett., 69, 309-332, 1998.

Kondo, H., Y. Awata, O. Emre, A. Dogan, S. Ozalp, F. Tokay, C. Yildirim, T. Yoshioka, and K. Okumura, Slip distribution, fault geometry, and fault segmentation of the 1944 Bolu-Gerede earthquake rupture, North Anatolian fault, Turkey, Bull. Seismol. Soc. Am., 95, 1234-1249, 2005.

Koto, B., On the cause of the great earthquake in central Japan, J. Coll. Sci., Imp. Univ. Tokyo, 5, 295-353, 1893.

Kumamoto, T., A. Okada, S. Toda, K. Ueda, and Y. Ikeda, Trenching study of the Neodani fault of the Nobi active fault system at Kinbara, Gifu Prefecture in 1991 (1991 nen Nobi katsudansokei Neodani danso (Kinbara chiku) torenchi chousa), Active Fault Res., 10, 85-91, 1992 (in Japanese).

Madariaga, R., On the relation between seismic moment and stress drop in the presence of stress and strength heterogeneity, J. Geophys. Res., 84(B5), 2243-2250, 1979.

Matsuda, T., Surface faults associated with Nobi (Mino-Owari) earthquake of 1891, Japan, Spec. Rep. Earthq. Res. Inst., 13, 85-126, 1974 (in Japanese).

McCalpin, J. P., Paleoseismology, 583 pp, Academic Press, 1996.

McGill, S. F. and C. M. Rubin, Surficial slip distribution on the central Emerson fault during the June 28, 1992, Landers earthquake, California, J. Geophys. Res., 104, 4811-4833, 1999.

Midorikawa, S., M. Matsuoka, and K. Sakugawa, Site effects on strong motion records observed during the 1987 Chiba-Ken-Toho-Oki, Japan Earthquake, Proceeding of 9th Japan Earthquake Engineering Symposium, E85-90, 1994.

Mikumo, T. and M. Ando, A search into the faulting mechanism of the 1891 great Nobi earthquake, J. Phys. Earth, 24, 63-87, 1976.

Miyakoshi, K., S. Ogata, T. Kakuda, Y. Satake, K. Tanaka, K. Kiho, Y. Inohara, and Y. Kanaori, Activity of the Neodani fault: characteristics and analysis of fault movement at Kinbara, Gifu Prefecture, Industry Report number U88052, Central Research Institute of Electric Power Industry, 1988 (in Japanese with English abstract).

Muramatu, I., Distribution of seismic intensity and crustal deformation in the region destroyed by the great Nobi earthquake of October 28, 1891, Res. Rep., Gifu Univ., 3, 202-224, 1963 (in Japanese).

Muramatu, I., Distribution of the percentage of collapsed houses in the Nobi plain for the Nobi earthquake of 1891, Res. Rep., Gifu Univ., 7, 867-882, 1983 (in Japanese with English abstract).

Muramatu, I. and M. Kominami, Collection of answers for a questionnaire investigation soon after the Nobi earthquake of 1891, Technical Note of the National Research Institute for Earth Science and Disaster Prevention, 155, 1-841, 1992 (in Japanese with English abstract).

Muramatu, I., T. Matsuda, and A. Okada, The 1891 Nobi Earthquake and Neo-dani Fault Zone, 340 pp, Kokon Shoin, 2002 (in Japanese).

Nakano, M., J. Miyakoshi, and K. Yamaoka, A new model for the fault beneath the sedimentary basin in the 1891 Nobi earthquake, Earth Planets Space, 59, 13-19, 2007.

Nakata, T., K. Shimazaki, Y. Suzuki, and E. Tsukuda, Fault branching and directivity of rupture propagation, J. Geogr., 107, 512-528, 1998 (in Japanese with English abstract).

Okada, A., M. Watanabe, M. Ando, T. Tsukuda, and S. Hirano, Estimation of paleo-seismicity in the Nobi active fault system, central Japan: excavation study of the Umehara fault, central strand in the Nobi active fault system, J. Geogr., 101, 1-18, 1992 (in Japanese with English abstract).

Omori, F., General Report on the Nobi Earthquake, Gifu Observatory, 4888,1894 (in Japanese).

Sato, H., A. Okada, T. Matsuda, and T. Kumamoto, Geology of a trench across the Midori fault scarp, from the Nobi earthquake of 1891, central Japan, J. Geogr., 101, 556-572, 1992 (in Japanese with English abstract).

Satoh, T., Radiation pattern and fmax of the Tottori-ken Seibu earthquake and the aftershocks inferred from KiK-net strong motion records, $J$. Struct. Constr. Eng., AIJ, 556, 25-34, 2002 (in Japanese with English abstract).

Satoh, T., H. Kawase, and T. Sato, Statistical spectral characteristics for 
engineering bedrock waves in which local site effects of surface geology are removed-Based on the ground motion records of small and medium earthquakes observed in the boreholes in Sendai-, J. Struct. Constr. Eng., AIJ, 462, 79-89, 1994 (in Japanese with English abstract).

$\mathrm{Si}, \mathrm{H}$. and S. Midorikawa, New attenuation relationships for peak ground acceleration and velocity considering effects of fault type and site condition, J. Struct. Constr. Eng., AIJ., 523, 63-70, 1999 (in Japanese with English abstract).

Sieh, K., The repetition of large-earthquake ruptures, Proc. Natl. Acad. Sci., 93, 3764-3771, 1996.

Somerville, P. G., K. Irikura, R. Graves, S. Sawada, D. Wald, N. Abrahamson, Y. Iwasaki, T. Kagawa, N. Smith, and A. Kowada, Characterizing crustal earthquake slip models for the prediction of strong ground motion, Seismol. Res. Lett., 70, 59-80, 1999.

Sugisaki, R. and K. Shibata, Geochemical study on ground water (I): subsurface geology and aquifers in the Nobi plain, J. Geol. Soc. Jpn., 67, 335-345, 1961 (in Japanese with English abstract).

Sugiyama, Y., H. Sekiguchi, Y. Awata, Y. Fukushima, and K. Shimokawa, Correlation analysis between active fault parameters, and heterogeneous source characteristics, Report for Study on the Master Model for Strong Ground Motion Prediction Toward Earthquake Disaster Mitigation, 119-129, 2002 (in Japanese).

The Headquarters for Earthquake Research Promotion, Evaluation of Gifu-Ichinomiya fault zone, http://www.jishin.go.jp/main/chousa/ 01jan2/index.htm, 2001 (in Japanese).

The Headquarters for Earthquake Research Promotion, Examination of strong ground motion prediction method based on recorded seismograms for the 2000 Western Tottori Prefecture earthquake, http://www.jishin.go.jp/main/chousa/02oct_tottori/index.htm, 2002 (in Japanese).

The Headquarters for Earthquake Research Promotion, Evaluation of strong ground motion for scenario earthquake in the Takayama and the Ohara fault zone, http://www.jishin.go.jp/main/ kyoshindo/04sep takayama/setsumei.pdf, 2004 (in Japanese).

The Headquarters for Earthquake Research Promotion, Evaluation of strong ground motion for scenario earthquake in the Yamasaki fault zone, http://www.jishin.go.jp/main/kyoshindo/05jan_yamasaki/ setsumei.pdf, 2005 (in Japanese).

The Headquarters for Earthquake Research Promotion, Examination of strong ground motion prediction method based on recorded seismograms for the 2005 West Off Fukuoka Prefecture earthquake, http://www.jishin.go.jp/main/kyoshindo/08apr_fukuoka/index. $\mathrm{htm}, 2008$ a (in Japanese).

The Headquarters for Earthquake Research Promotion, Strong ground motion prediction method ("Recipe") for earthquakes with specified source faults, http://www.jishin.go.jp/main/kyoshindo/08apr_kego/recipe.pdf, 2008b (in Japanese).

The Research Group for Active Faults of Japan, Active Faults in Japan, $437 \mathrm{pp}$, University of Tokyo Press, 1991.

Wald, D. and T. Heaton, Spatial and temporal distribution of slip for the 1992 Landers, California, earthquake, Bull. Seismol. Soc. Am., 84, 668691, 1994.

Wells, D. L. and K. J. Coppersmith, New empirical relationships among magnitude, rupture length, rupture width, rupture area, and surface displacement, Bull. Seismol. Soc. Am., 84, 974-1002, 1994.

Wesnousky, S. G., Displacement and geometrical characteristics of earthquake surface ruptures: Issues and implications for seismic-hazard analysis and the process of earthquake rupture, Bull. Seismol. Soc. Am., 98, $1609-1632,2008$

Wessel, P. and W. H. F. Smith, New, improved version of the Generic Mapping Tools released, Eos Trans. AGU, 79, 579, 1998.

Working Group on California Earthquake Probabilities, Seismic hazards in Southern California; Probable earthquake, 1994 to 2024, Bull. Seismol. Soc. Am., 85, 379-439, 1995.

Yoshioka, T., Y. Awata, K. Shimokawa, H. Ishimoto, M. Yoshimura, and K. Matsuura, Paleoseismological study of the Nukumi fault, the 1891 Nobi earthquake fault system, central Japan, Annual Report on Active Fault and Paleoearthquake Researches, 1, 97-105, 2001 (in Japanese with English abstract).

M. Kuriyama (e-mail: kuriyama@criepi.denken.or.jp) and T. Iwata 